\title{
Life Cycle Assessment of Lithium Sulfur Battery for
}

\section{Electric Vehicles}

\author{
Yelin Deng, ${ }^{1}$ Jianyang Li, ${ }^{1}$ Tonghui Li ${ }^{1}$ Xianfeng Gao, ${ }^{1}$ Chris Yuan ${ }^{1,2, *}$
}

${ }^{1}$ Department of Mechanical Engineering, University of Wisconsin, Milwaukee, WI, the United States

${ }^{2}$ Department of Mechanical and Aerospace Engineering, Case Western Reserve University, $\mathrm{OH}$, the United States

*Corresponding author: chris.yuan@ case.edu

ABSTRACT Lithium-sulfur (Li-S) battery is widely recognized as the most promising battery technology for future electric vehicles (EV). To understand the environmental sustainability performance of Li-S battery on future EVs, here a novel life cycle assessment (LCA) model is developed for comprehensive environmental impact assessment of a Li-S battery pack using a graphene sulfur composite cathode and a lithium metal anode protected by a lithium-ion conductive layer, for actual EV applications. The Li-S battery pack is configured with a 61.3 $\mathrm{kWh}$ capacity to power a mid-size EV for $320 \mathrm{~km}$ range. The life cycle inventory model is developed with a hybrid approach, based on our lab-scale synthesis of the graphene sulfur composite, our lab fabrication of Li-S battery cell, and our industrial partner's battery production processes. The impacts of the Li-S battery are assessed using the ReCiPe method and benchmarked with those of a conventional Nickle-Cobalt-Manganese (NCM)-Graphite battery pack under the same driving distance per charge. The environmental impact assessment results illustrate that Li-S battery is more environmentally friendly than conventional NCM-Graphite 
battery, with $9 \% \sim 90 \%$ lower impact. Finally, the improvement pathways for the Li-S battery to meet the USABC (U.S. Advanced Battery Consortium) targets are presented with the corresponding environmental impact changes.

Keyword: Lithium sulfur battery, graphene wrapped sulfur, lithium metal anode, life cycle assessment, environmental impact

\section{Introduction}

The ground transportation sector generates approximately $27 \%$ of the total greenhouse gas (GHG) emissions in the U.S [1]. To address global warming concerns, the U.S. EPA has set a regulatory standard to reduce the average GHG emissions of the U.S. light passenger vehicles from $225 \mathrm{~g} \mathrm{mile}^{-1}$ in 2016 to $143 \mathrm{~g} \mathrm{mile}^{-1}$ in 2025 [2], mainly to be achieved through adoption of electric vehicles (EVs) [3-5]. Current EVs are all powered by lithium ion batteries (LIBs) due to their high energy density and higher power density relative to other battery technologies. However, with 80-150 Wh kg ${ }^{-1}$ energy density [6-8], current LIBs on board of EVs are not able to power the EVs for a comparable driving range with conventional vehicles. Meanwhile, current LIB technologies generate significant environmental impacts during their life cycle. For example, current LIBs consume 1141-1224 MJ-equivalent energy and generate 57-85 $\mathrm{kg} \mathrm{CO}_{2}$ equivalent emissions per kg battery during their life cycle $[9,10]$. Recent years have witnessed rapid progress on the research and development of next-generation battery technologies with higher energy density and better environmental performance.

Among various battery technologies under development, lithium-sulfur (Li-S) battery is widely recognized among the most promising battery technologies for next generation EVs [1114]. Compared to the conventional Li-ion battery, Li-S battery offers a much higher energy 
density, i.e., sulfur with a specific capacity of $1672 \mathrm{mAh} \mathrm{g}^{-1}$ [14], corresponding to a high theoretical energy density of $\sim 2600 \mathrm{Wh} \mathrm{kg}^{-1}$. Besides, sulfur is abundantly available in nature and often considered as a more environmentally benign material than those heavy metals used in conventional lithium-ion batteries [15].

Li-S batteries have been facing some technical challenges, including rapid capacity fading due to the dissolution of sulfur active materials from the polysulfide shuttle effect, low ionic and electronic conductivity of the sulfur material, and low coulombic efficiency and dentrite growth of lithium metal anode, which all affect the battery life and cause safety hazard $[12,14,16]$. After recent years of intensive research and development, these technical challenges can now be effectively addressed. The dissolution of sulfur problem in Li-S batteries can be suppressed by confining the sulfur in thin film layered materials such as graphene [17-20]. Graphene including reduced graphene oxide has such functional groups as hydroxyl, carboxyl and ester groups which can effectively bind $\mathrm{S}_{8}$ and polysulfide species, and hence to successfully trap polysulfide from dissolution [21]. It has been reported that the graphene-sulfur composite (GSC) with nitrogen-doping can achieve a stable cycling performance up to 1440 $\mathrm{mAh} \mathrm{g}^{-1}$ with a decay rate as low as $0.028 \%$ over 2000 cycles [22]. Another study demonstrates that depositing nanosulfur on graphene layers can result in a low capacity fading of $0.039 \%$ per cycle over 1500 cycles in an ionic liquid electrolyte [23,24]. Recently, a water-based solution precipitation method has been developed for GSC production with a high yield rate, which eliminates the use of toxic solvents and is regarded as a low-cost and environmentalfriendly process, with promising potential for future industrial-scale productions $[20,22,25]$. The low conductivity problem of sulfur can be resolved by adding such conductive additives as carbon black, carbon nanotubes, etc. in the active material [14]. 
The low coulumbic efficiency and safety concerns of using a lithium metal anode in the Li-S battery can be addressed by the formation of a passivation layer on the lithium metal surface to isolate the anode from undesired side reactions to suppress dendrite growth and improving coulumbic efficiency [16,26-28]. The passivation layer in nature is a lithium ion conducting ceramic membrane[29] that can be artificially produced by treating the lithium metal surface with such chemicals as tetraethoxysilane (TEOS) [30], chlorosilane [31], nitrogen [32], etc. In another way, a thin layer of materials including interconnected hollow carbon spheres [28], polymer nanofibres [33] and metal oxides [34] can also be coated onto the lithium metal surface prior to cell manufacturing to obtain the protective effect. Recently, the atomic layer deposition (ALD) technology has been applied for lithium metal anode protection through depositing a thin layer of $\mathrm{Al}_{2} \mathrm{O}_{3}$ [34]. In addition, $\mathrm{LiNO}_{3}$ can be added into the lithium bistrifluoromethanesulfonimidate (LiTFSI) electrolyte in the dimethyl glycol (DME) and Dioxolane (DOL) solution to enhance the formation of the protective layer by reacting with the polysulfide species and lithium metal material [16,35]. It is also reported that adding $\mathrm{LiNO}_{3}$ into the LiTFSI electrolyte can greatly improve the safety performance of the lithium metal anode in Li-S batteries [23] and also can substantially reduce the self-discharging of Li-S batteries from over $10 \%$ per day to less than $2 \%$ per month [36-38]. All these technical advances have prepared the Li-S battery as a promising alternative to the conventional Li-ion battery for next generation EV applications.

Li-S batteries are ready to enter commercial production for next generation EV applications [39-41]. The European Union has launched an Advanced Lithium Sulphur battery for EV (ALISE) project to promote the applications of Li-S battery on EVs in future. Current industrial prototypes of Li-S battery have already achieved $300 \mathrm{Wh} \mathrm{kg}^{-1}$ at the cell level and 200 
$\mathrm{Wh} \mathrm{kg}^{-1}$ at the battery pack level, almost twice of conventional LIBs on EVs [40]. While Li-S battery is promising for next generation EV applications, the life cycle environmental impacts of Li-S batteries have never been studied and understood. The Li-S battery uses a wide variety of toxic chemicals in the electrode/electrolyte material synthesis and manufacturing processes, including hydrogen fluoride, sulfuric acid, hydrogen chloride, etc. Besides, the Li-S battery requires energy-intensive processes for the electrode materials and cell manufacturing. For instance, the synthesis of the GSC involves 1-2 hours of sonication of the GSC solution with an energy input of $140-300 \mathrm{~kW}$ per cubic meter $[42,43]$; battery cell manufacturing requires a 100 $150^{\circ} \mathrm{C}$ process heating to evaporate off the NMP solvent through around 8 hours of continuous operation [44], as well as dry room facility to maintain a moisture level less than $100 \mathrm{ppm}$. As the Li-S battery is rapidly moving toward commercial-scale production, it is important to perform a comprehensive life cycle assessment (LCA) of Li-S battery technology to quantify and understand its potential environmental impacts.

In this paper, we developed a hybrid LCA model for an Li-S battery pack for EV application, using a graphene-sulfur cathode, a lithium metal anode, and LiTFSI electrolyte. The graphene-sulfur synthesis is modelled from our lab-scale fabrication process, and the battery cell manufacturing processes are modelled with actual data collected from our industrial partner's pilot scale production facilities. The life cycle environmental impacts are assessed by the ReCiPe method [45]. To understand the relative significance of the impacts, the life cycle environmental impacts of the Li-S battery are benchmarked with those of a conventional LIB pack using a Lithium-Nickel-Cobalt-Manganese oxide cathode and a graphite anode (NCM-Graphite). The LCA results can be useful in sustainable design and manufacturing of Li-S battery packs for future EV applications. 


\section{Method}

\subsection{Li-S battery pack configuration for a mid-size EV}

The Li-S battery pack in this study is configured to power a mid-size EV for a $320 \mathrm{~km}$ driving distance (D) per charge with $120 \mathrm{~kW}$ power (Figure 1, Section 1 and calculations supplied in the electronic supporting information (ESI) for details) [46]. For the battery system configuration, first, the battery energy for traction at wheel $\left(\mathrm{E}_{\text {traction, }, i}\right)$ is calculated for the EV at various speeds under both highway and local driving conditions, respectively, using the EPA Urban Dynamometer Driving Schedule (UDDS) and Highway Fuel Economy Test (HWFET) patterns (Section 1.1 in the ESI) [47]. The amount of energy discharged ( $E_{\text {discharged, }}$ ) from the LiS battery pack is the sum of traction energy divided by the product of motor efficiency $\left(\eta_{\text {motor }}\right)$ and the EV transmission efficiency $\left(\eta_{\text {transmission }}\right)$, plus the energy consumed by the auxiliary system $\left(P_{a u x}\right)$. The specific energy consumption is the ratio of the discharged energy $\left(\mathrm{E}_{\mathrm{discharged}, \mathrm{i}}\right)$ over the distance of the driving schedule $\left(\mathrm{s}_{\mathrm{i}}\right)$. Afterwards, the composite discharged energy $\left(\mathrm{E}_{\text {discharged }}\right)$ is the weighted-sum of specific energy consumptions. The weight factors $(a: b)$ is set to be $45 \%: 55 \%$, which is the distance ratio of local and highway driving under the U.S. national average [48]. Finally, the nominal capacity of the Li-S battery pack, with $85 \%$ accessible fraction by user (UR), is calculated as the ratio between the amount of energy discharged from the battery pack and the battery discharging efficiency $\left(\left(\eta_{\text {disc harging }}\right)\right.$, while the total energy drawn from the wall outlet can be calculated as the ratio of the stored energy $\left(\mathrm{E}_{\text {stored }}\right)$ over the product of battery charging $\left(\left(\eta_{\text {charing }}\right)\right.$ and charger efficiencies. The vehicle mass $(\mathrm{M})$, as required for $\mathrm{E}_{\text {traction }}$ calculation, consists of glider, transmission, motor, and battery masses [49]. Transmission and motor masses are calculated according to mass-power coefficients, namely, $0.585 \mathrm{~kg}$ 
transmission $\mathrm{kW}^{-1}$ and $0.9 \mathrm{~kg}$ motor $\mathrm{kW}^{-1}$ [49]. Glider mass is derived based on a baseline electric vehicle and mass compounding coefficient of $0.57 \mathrm{~kg}$ change in glider mass per $\mathrm{kg}$ change in powertrain mass [50]. Finally, the battery mass is calculated as the ratio between the nominal battery pack and energy density $\left(\sigma_{L i-S}\right)$ of the Li-S battery.

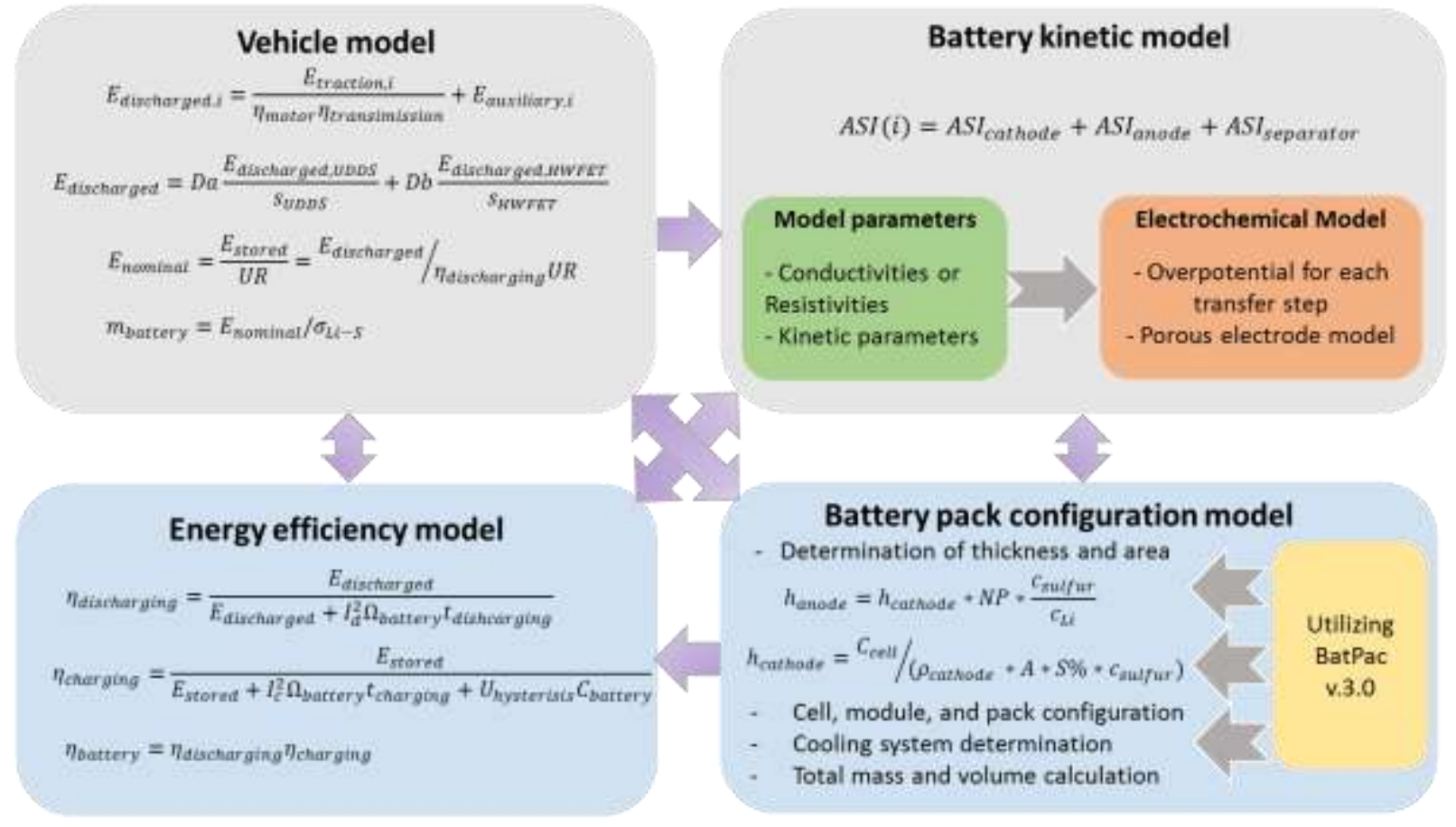

Figure 1 Energy flows and efficiencies of EV powered by Li-S battery pack. Detailed information is provided in Section 1 in ESI. The entire calculation is presented in the excel spreadsheet.

The battery discharging and charging efficiencies are determined considering the heat loss induced by the battery resistance $\left(\Omega_{\text {battery }}\right)$, with Joule's law being used, considering the

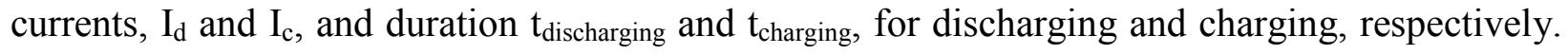
For the charging process, besides energy loss on battery resistance, hysteresis loss is also included. A range of $170 \mathrm{mV}-400 \mathrm{mV}$ open-circuit voltage $(\mathrm{OCV})$ difference is recorded for the 
Li-S battery cell [51-53]. Then, the hysteresis loss is calculated as the product of the overall battery voltage hysteresis $\left(\mathrm{U}_{\text {hysteresis }}\right)$ and the battery capacity $\left(\mathrm{C}_{\text {battery }}\right)$.

Determination of $\sigma_{L i-S}$ is based on the configuration of the Li-S battery. The Li-S battery pack is configured with stacked battery cells, a battery management system (BMS), a battery cooling system, and battery packaging. The BatPac, a battery design software developed by Argonne National Lab [46], is adapted to model the Li-S structure in this study (Section 1.2 and Section 1.3 in ESI) [25]. In the BatPac method, the area specific impedances (ASIs) of the electrode system at constant discharging for energy use and pulse power discharging for power use are two important parameters. The electrode ASI is calculated as a function of current density (i) from the polarization behavior [54]. A battery kinetic model is built to quantify the ASIs caused by charge transfer and conduction phenomenon in each step of the electrochemical cell under current densities at energy $\left(i_{E}\right)$ and power $\left(i_{p}\right)$ use. Other technical parameters of the Li-S chemistry in the BatPac modeling are based on current lab-scale experimental data. The cathode is porous structure composed of graphene-sulfur composite (GSC), carbon black, and PVDF binder at 7:2:1. The specific capacity of the sulfur ( $\mathrm{c}_{\text {sulfur }}$ ) is $1200 \mathrm{mAh} \mathrm{g}^{-1} \mathrm{~S}$ with $56 \mathrm{wt} \%$ sulfur loading in the cathode (S\%) [54]. For the Li-S battery, a volume fraction range of 50\%-90\% of electrolyte over the total cathode is normally recommended [21]. In this study, $60 \%$ volume fraction of the electrolyte is used based on our experiments. The anode is made of a lithium metal with a surface protective layer. For the entire anode, we consider 50\% access of the lithium metal $(N P=1.5)$ with $3861 \mathrm{mAh} \mathrm{g}^{-1}$ specific capacity $\left(c_{L i}\right)$ compressed onto a $8 \mu \mathrm{m}$ copper collector [28,55]. A conventional trilayer separator (polypropylene-polyethylene-polypropylene) with $20 \mu m$ thickness and $39 \%$ porosity is used. The cell container consists of a multilayer polymer pouch covering the cell layers, and two terminals made of aluminum and copper. 
Through the BatPac calculation (Figure 1) a $61.3 \mathrm{kWh}$ Li-S battery pack containing 12 modules each with 28 cells is configured. Each cell has 87.5 Ah capacity and is weighted at 547 g. The mass of the total battery pack is $279 \mathrm{~kg}$, including $184 \mathrm{~kg}$ cells, $4 \mathrm{~kg}$ BMS, $27 \mathrm{~kg}$ cooling system, $23 \mathrm{~kg}$ module packaging, and $41 \mathrm{~kg}$ pack packaging. Meanwhile, the battery efficiency $\left(\eta_{\text {battery }}\right)$ is calculated at $86 \%$ at a low $200 \mathrm{mV}$ voltage hysteresis. This value is in line with the 78\%-91\% energy efficiency measured for the Li-S battery cell [56].

For the reference battery system, the NCM-Graphite battery pack is modelled at $120 \mathrm{Wh}$ $\mathrm{kg}^{-1}$ gravimetric energy density, representing the average of the $105-140 \mathrm{Wh} \mathrm{kg}^{-1}$ range as reported in literature $[7,46]$. Accordingly, this NCM-Graphite battery has a $63.8 \mathrm{kWh}$ capacity to power the EV for $320 \mathrm{~km}$ per charge. This is in good agreement with previous industrial studies which states that a conventional LIB battery pack needs $56-75 \mathrm{kWh}$ capacity to power an EV for $320 \mathrm{~km}$ driving distance per charge [57,58]. Table 1 summarizes the battery information and parameters for both the configured Li-S battery pack and the reference NCM-Graphite battery pack in this study. Li-S and NCM-graphite battery packs are estimated to represent $17 \%$ and $26 \%$ of the entire vehicle mass, respectively. The fractions are in line with the current EV design where battery consists of $15 \% \sim 25 \%$ of total mass for a midsized vehicle [59].

Table 1 Comparison of technical parameters between the Li-S and reference battery pack

\begin{tabular}{ccc}
\hline Parameters & Li-S & NCM-Graphite \\
\hline Battery mass $(\mathrm{kg})$ & 279 & 531 \\
Gravimetric energy density $\left(\mathrm{Wh} \mathrm{kg}^{-1}\right.$ battery) & 220 & 120 \\
Volumetric energy density $\left(\mathrm{Wh} \mathrm{L}^{-1}\right)$ & 298 & 350 \\
$\mathrm{UR}$ & $85 \%$ & $85 \%$ \\
Capacity $(\mathrm{kWh})$ & 61.3 & 63.8 \\
\hline
\end{tabular}




\begin{tabular}{ccc}
\hline Corresponding Vehicle mass $(\mathrm{kg})$ & 1625 & 2021 \\
\hline Driving distance per charge $(\mathrm{km})$ & 320 & 320 \\
\hline
\end{tabular}

\subsection{Life Cycle Assessment of the Li-S battery}


A hybrid LCA model is developed in this study to analyze and understand the potential environmental impacts of Li-S battery technology for actual EV applications. An overview of the LCA system boundaries is illustrated in Figure 2. The life cycle of the Li-S battery pack is divided into five stages: raw materials extraction, materials processing, battery manufacturing, battery use, and end-of-life (EoL). The functional unit of the LCA is set per kilometer driving for a mid-sized EV powered by the Li-S battery pack. Based on the current lab-scale performance of the Li-S battery and the measured capacity fading rate, the overall driving distance of the EV is set at $200,000 \mathrm{~km}$ during the life cycle of the Li-S battery. In this LCA study, the environmental impacts of the material and energy consumption, as well as waste and emissions directly associated with each life cycle stage of the Li-S battery are quantitatively evaluated (Figure 1). At the final EoL stage, battery recycling is modeled based on a hydrometallurgical process for material recovery, while recycling credit is not considered in this study because the recycled materials may not meet the high-quality standards of materials for battery manufacturing [10].

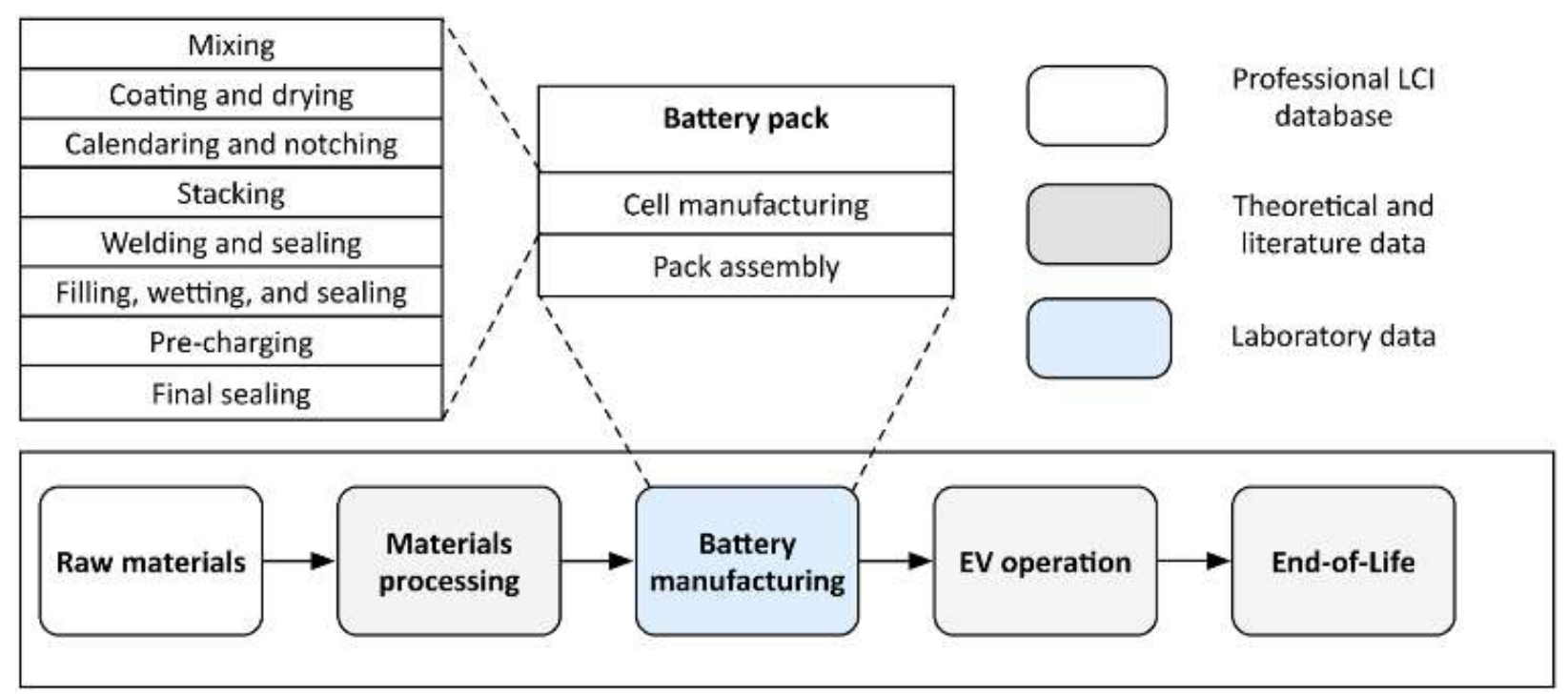

Figure 2 Scope and boundary of the LCA for the Li-S battery. 
The ReCiPe method is adopted to derive both the midpoint environmental impacts and endpoint environmental impacts for the configured Li-S battery pack. With the ReCiPe method, the environmental impacts are quantified into 13 midpoint impact categories, including global warming (GWP), fossil depletion (FDP), ozone depletion (ODP), photochemical oxidant formation (POFP), particulate matter formation (PMFP), terrestrial acidification (TAP), freshwater eutrophication (FEP), marine eutrophication (MEP), freshwater ecotoxicity (FETP), marine ecotoxicity (METP), terrestrial ecotoxicity (TETP), human toxicity (HTP), metal depletion (MDP). Besides, in order to evaluate the environmental impacts of the novel GO nanomaterial, which cannot be assessed through the traditional ReCiPe method, we have developed a modified USEtox method to characterize the freshwater ecotoxicity of GO after it is released into the U.S. environment, based on recent toxicity studies of GO nanomaterials [60].

\subsection{Inventory analysis for the Li-S battery}

Table S5 and S6 in the ESI provide an overview of the materials and energy inputs for inventory of the Li-S battery pack. For the inventory analysis of such materials as current collector, multilayer pouch and terminals, cooling system, module and pack level packaging, inventories are constructed based on the outputs from the BatPac method (see Section 2 in the ESI). For inventory analysis of the GSC, lithium film, electrolyte (LiTFSI, DOL, $\mathrm{LiNO}_{3}$ ) and Li$\mathrm{S}$ cell manufacturing, we have developed process-based inventory models as presented below, with details provided in Section 2 of the ESI.

\subsubsection{Inventory analysis for the Li-S battery}

A hybrid inventory analysis model is developed in this study integrating our lab experimentation and theoretical modelling methods to compile the inventory data for Li-S 
battery materials. Production of GSC and graphene oxide are modelled based on our lab scale experiments [25] and the Hummers' method [61], respectively (Section 2.2 and Section 2.3 in ESI). The material input inventories of the two materials production are linearly extrapolated from the lab scale data assuming a $98.5 \%$ efficiency from typical industrial tubular centrifuges [62]. The energy consumption of materials production are modelled according to the specific energy consumptions (SEC) of relevant unit processes (baseline consumption, stirring, reaction heating, centrifugation, and drying). The SECs of these basic unit processes are calculated based on conventional mechanical and thermal methods or directly used industrial data [63-66]. Finally, the absolute energy consumption of the unit processes is obtained by multiplying the SEC with the mass/volume of the materials being processed. No heat recovery is considered for the two materials production since both reactions are below $100^{\circ} \mathrm{C}$ [67].

Inventories of the lithium metal anode and the LiTFSI electrolyte were constructed by modelling their unit production processes and relevant data are compiled from literature and the Ecoinvent database (Section 2.5 and Section 2.6 of the ESI). The inventory of the lithium metal anode involves the unit processes of lithium film production and the following surface treatment for forming a protective layer (Section 2.5 in the ESI). Commercial production of lithium film is made by extruding lithium metal through a slit [67], followed by a sheet rolling process [68]. In this study, the extrusion process is modelled based on the mechanical model, and the cold sheet rolling of steel available in the Ecoinvent database was converted into lithium cold rolling based on the density ratio of the two materials. The inventory of the protective layer on the surface of the lithium metal anode was modelled as a surface treatment process using TEOS resulting in a $1000 \mathrm{~nm}$ lithium-ion conducting membrane formed at a density of $2.96 \mathrm{~g} \mathrm{~cm}^{-3}$ [28]. Production of LiTFSI was modelled according to the synthetic route from trifluorometansulfonyl fluoride 
$\left(\mathrm{CF}_{3} \mathrm{SO}_{2} \mathrm{~F}\right)$ [69], which is produced through electrochemical fluorination (ECF) of methanesulfonyl chloride $\left(\mathrm{CH}_{3} \mathrm{SO}_{2} \mathrm{~F}\right)$ with liquid hydrofluoric acid (HF) [70].

\subsubsection{Inventory analysis of battery pack production process.}

After the electrode materials are fabricated, the Li-S battery cell is manufactured through similar processes as the conventional NCM-Graphite battery cell (Section 2.8 in the ESI). In this study, we have obtained the energy demand of the Li-S cell manufacturing through measuring and modelling the energy consumption of battery manufacturing equipment in a $93.2 \mathrm{~m}^{2}$ pilot scale dry room facility of Johnson Controls Inc. (Figure S11 and Section 2.8 in the ESI). As calculated, the electricity consumption of a configured $87.5 \mathrm{Ah} \mathrm{Li-S}$ cell is $46.6 \mathrm{kWh} \mathrm{kg}^{-1}$, including $27.2 \mathrm{kWh} \mathrm{kg}^{-1}$ for the cell manufacturing processes and $19.4 \mathrm{kWh} \mathrm{kg}^{-1}$ for the supporting dry room. The subsequent battery pack assembly is mainly performed manually with $3.9 \mathrm{Wh} \mathrm{kg}^{-1}$ consumed during the battery pack assembly process [7].

As Li-S batteries are now at an early stage of commercialization, the pilot scale production can represent the near future situation of Li-S battery manufacturing. In regards to the future large-scale industrial production of Li-S batteries, the energy consumption will be even lower. To evaluate and benchmark the energy use of Li-S battery production at both pilot scale and industrial scale, here the Li-S battery manufacturing is divided into unit manufacturing processes, including active material mixing, slurry coating, drying, calendering, notching, stacking, filling, welding, degassing, and packaging. The specific energy consumptions of each unit manufacturing process at an industrial scale are compiled based on corresponding industrial production data in literature (Table S20 in the ESI). Finally, the energy consumption of Li-S battery production at industrial scale is estimated in the range of $11.3-22.8 \mathrm{kWh} \mathrm{kg}^{-1} \mathrm{Li}-\mathrm{S}$ cell. 
The material inventory of the Li-S battery production is analyzed based on the mass compositions of the $87.5 \mathrm{Ah}$ Li-S battery cell and the $61.3 \mathrm{kWh}$ battery pack (Section 2.1 in the ESI). The material inputs are subsequently calculated based on the material efficiencies of the cell manufacturing process. It is expected that efficiencies of Li-S battery cell manufacturing resemble those in conventional LIB cell manufacturing, namely, 92\% for the positive and negative electrodes, $98 \%$ for the separator, and $94 \%$ for the electrolyte [71]. In addition, the PVDF binder needs to be dissolved in NMP solvent at $8 \mathrm{wt} \%$ to produce the cathode slurry, with the NMP solvent recovered at a $98 \%$ efficiency. For the $61.3 \mathrm{kWh}$ Li-S battery pack, 336 pouch cells are stacked and packaged in 12 modules with the BMS and battery cooling system. Finally, all of the modules are situated in the aluminium based pack housing and closed with a steel strap. Detailed inventory data for cell container (including pouch and terminals) are provided in ESI section 2.7, and inventory data for the module and pack packagings are provided in ESI section 2.9. Inventory data for BMS is based on the information in Ellingsen et al [7].

\subsubsection{Inventory analysis of battery use.}

The inventory for the Li-S battery use phase is analysed for actual EV operations under average U.S conditions, with the Li-S battery life considered first. With the Li-S battery degradation, the total driving distance, $\mathrm{T}_{\mathrm{s}}$, of the Li-S battery pack can be calculated through [7]

$$
T_{s}=D_{0}\left(c-\frac{r c^{2}}{2}\right)
$$

where $\mathrm{D}_{0}$ is the initial driving distance per charge $(320 \mathrm{~km}), \mathrm{c}$ is the cycling number; and $\mathrm{r}$ is the capacity decay rate. Using an experimentally determined $0.028 \%$ capacity loss per cycle as the decay rate [22], and assuming a battery replacement needed when the capacity drops down to $70 \%$ of its original level, the $T_{s}$ is calculated around $290,000 \mathrm{~km}$ using Equation (1). However, it is noted that in this calculation, calendar loss from Li-S battery aging is not considered, which in 
fact causes additional capacity fading during the battery use phase and will shorten the total driving miles. As currently no study has been conducted on calendar loss of Li-S battery pack for EVs, here we assume the decay rate from Li-S calendar loss is at the same level with that of its cycling loss. Consequently, the actual drivable miles during the service life of the Li-S battery pack is set at 200,000 miles for about 10 years of service life under average U.S. driving conditions [72], according to equation (2). In this case, a single Li-S battery pack can be used to power the EV during the designed service life, with no battery replacement needed. The possible variations of battery decay rates and the resulting battery life are investigated in the later sensitivity analysis.

Then the inventory analysis for the Li-S battery use phase is based mainly on the electricity consumption during EV operations. In this study, the U.S. average electric grid is considered for electricity generation. The operation of the EV is $55 \%$ city and $45 \%$ highway driving, based on the U.S. national average data [48]. The electricity consumption of the Li-S battery during the use phase can be calculated through:

$$
E_{\text {use }}=\frac{E_{\text {disc harged }}}{D \eta_{\text {battery }} \eta_{\text {charger }}} T
$$

Calculation of the discharged energy ( $\left.E_{\text {discharged }}\right)$ is provided in Section 1 in the ESI. Charger efficiency $\left(\eta_{\text {charger }}\right)$ is 0.90 [73]. Battery efficiency $\left(\eta_{\text {battery }}\right)$ equals $\eta_{\text {discharging }} \times$ $\eta_{\text {charging }}$, respectively. $\mathrm{T}$ is the total driving distance.

\subsubsection{Inventory analysis of battery EoL.}

Recycling of Li-S battery at the EoL of the EV is modelled from EV collection, battery removal, discharging, battery disassembly, materials shredding/sorting, until materials refining/disposal. The collection rate of EVs is taken at a generalized rate of $91 \%$ from literature 
[74]. After that, the Li-S battery packs are removed from the vehicle and discharged in a salt solution to deplete the residual energy [71]. Since Li-S batteries do not contain precious transit metals (e.g. cobalt), a hydrometallurgical recycling process is adopted in this study [71]. Detailed information on the inventory of the Li-S battery hydrometallurgical recycling process is provided in Section 2.10 in the ESI.

\subsubsection{Reference battery system.}

In this study, a conventional $63.8 \mathrm{kWh} \mathrm{NCM}$-Graphite battery is configured as a reference battery system for benchmarking and validating our results on the $61.3 \mathrm{kWh} \mathrm{Li-S}$ battery. The LCA data and results from Ellingsen et al. on the NCM-Graphite battery for EVs is adapted, using the same ReCiPe method [45]. In this study, the unit LCA results from Ellingsen's study are linearly scaled up to our configured NCM-Graphite battery $(63.8 \mathrm{kWh})$, for comparison with our Li-S battery results.

3. Results and Discussion

3.1 Life Cycle Inventory of the Li-S battery pack

The life cycle inventory analysis results for the configured Li-S battery pack are compiled for both material and inventory data. The material inventory provides masses of all materials needed to produce the Li-S battery pack during its whole life cycle (Table 2). As calculated, a total of $471 \mathrm{~kg}$ of material inputs is required during the life cycle of the $279 \mathrm{~kg} \mathrm{Li}-\mathrm{S}$ battery pack. From the inventory analysis, the GSC based positive electrode is the most material demanding component in the Li-S battery pack, which requires $49.2 \%$ of total material inputs. Each gram of GSC synthesis requires $0.158 \mathrm{~g} \mathrm{GO}, 4.00 \mathrm{~g}$ sodium thiosulfate, $0.063 \mathrm{~g} \mathrm{PVP}$, and $1.85 \mathrm{~g} \mathrm{HCl}$ acid (Table 2), from which the sodium thiosulfate and $\mathrm{HCl}$ acid combined together account for $41.3 \%$ of total material flow. Meanwhile, synthesis of GSC results in 0.266 liters of 
wastewater flow for each gram of GSC synthesized. In comparison, production of the lithium foil anode and the passivation layer only accounts for $6.1 \%$ of the material flow due to the high efficiency of material utilization during the process, with $97.5 \%$ for extrusion and $99 \%$ for cold rolling.

The electrolyte requires $14.3 \%$ of total material inputs. The electrolyte includes $10.8 \mathrm{~kg}$ LiTFSI salt and $55.9 \mathrm{~kg}$ DOL/DME solvent. During the Li-S battery life cycle. The LiTFSI takes up only $2.3 \%$ of total battery material inputs, but it involves $0.57 \mathrm{~g}$ of $\mathrm{HF}$ toxic chemical and generates $3.57 \mathrm{~g}$ hazardous wastes per gram of LiTFSI production(Table S12 in ESI).

In the Li-S battery pack, common plastics including $3.6 \mathrm{~kg} \mathrm{PE}$ (polyethylene) and $6.5 \mathrm{~kg}$ PP (polypropylene) are used, mainly for the separator in the Li-S cell as well as the trilayer pouch. The injection moulding and compression moulding processes are modelled for their production. In addition, a total amount of $86.6 \mathrm{~kg}$ aluminium (18\% of total material inputs) is used for the Li-S battery with a distribution of produce pack housing (49\%), inner and outer frames of cells in modules (16\%), positive electrode current collector (16\%), radiators in the cooling system (9\%). The cooling system contains $20 \mathrm{~kg}$ ethylene glycol, determined through heat generation rate during battery operations. In the calculation, we set a criteria that the coolant amount should be sufficient to enable no more than $1^{\circ} \mathrm{C}$ increase of battery temperature when the EV is driving at a fast mode of $85 \mathrm{mph}$.

Copper use, as the main toxicity concerns for conventional LIB [7], is relatively limited in the Li-S battery. A total of $36.8 \mathrm{~kg}$ copper including the mass of copper wire, is used in the $\mathrm{Li}$ $\mathrm{S}$ battery pack, representing a unit rate of $0.6 \mathrm{~kg}$ copper use per $\mathrm{kWh} \mathrm{Li}-\mathrm{S}$ battery capacity. When compared, the conventional LIB battery has a copper concentration of $1.33 \mathrm{~kg}$ per $\mathrm{kWh}$ capacity 
[7]. In addition, a total of $2.5 \mathrm{~kg}$ steel is used in the battery pack, which are used to produce strap for pack packaging.

Table 2 Material inputs inventory for the $61.3 \mathrm{kWh}$ Li-S battery pack production

\begin{tabular}{|c|c|c|c|}
\hline & Quantity (kg) & Weight ratio $(\%)$ & Comment \\
\hline \multicolumn{4}{|l|}{ Positive electrode } \\
\hline Graphene oxide & 5.3 & $1.12 \%$ & Input materials for GSC synthesis \\
\hline Sodium thiosulfate & 132.9 & $28.25 \%$ & Sulfur donor \\
\hline PVP & 2.1 & $0.45 \%$ & Additive, controlling sulfur size \\
\hline $\mathrm{HCl}$ & 61.4 & $13.06 \%$ & \\
\hline Carbon black & 9.5 & $2.02 \%$ & $20 \mathrm{wt} \%$ of cathode \\
\hline PVDF & 4.7 & $1.01 \%$ & $10 \mathrm{wt} \%$ of cathode, in $8 \mathrm{wt} \%$ NMP solution \\
\hline Aluminium, ingot & 14.2 & $3.02 \%$ & Current collector, $15 \mu \mathrm{m}$ thickness \\
\hline NMP & 1.1 & $0.23 \%$ & Solvent for PVDF binder. \\
\hline \multicolumn{4}{|l|}{ Negative electrode } \\
\hline lithium, billet, primary & 13.5 & $2.87 \%$ & \\
\hline TEOS & 2.5 & $0.43 \%$ & $20 \mathrm{wt} \%$ of TEOS are lost during surface treatment \\
\hline Copper, billet & 24.2 & $5.14 \%$ & Current collector, $8 \mu \mathrm{m}$ thickness \\
\hline \multicolumn{4}{|l|}{ Separator } \\
\hline PP & 4.8 & $1.03 \%$ & $20 \mu \mathrm{m}$ trilayer separator, $39 \mathrm{vt} \%$ porosity \\
\hline $\mathrm{PE}$ & 2.4 & $0.51 \%$ & \\
\hline \multicolumn{4}{|l|}{ Electrolyte } \\
\hline LiTFSI & 10.8 & $2.29 \%$ & 1M LiFTSI in DOL/DME solvent \\
\hline DOL & 19.5 & $4.15 \%$ & Organic solvent at $1: 1$ ratio by volume \\
\hline DME & 36.3 & $7.73 \%$ & \\
\hline $\mathrm{LiNO}_{3}$ & 0.7 & $0.14 \%$ & Additive, at $1 \mathrm{wt} \%$ fraction of electrolyte system \\
\hline \multicolumn{4}{|l|}{ Cell container } \\
\hline Aluminium, ingot & 5.7 & $1.21 \%$ & Production of the trilayer pouch \\
\hline PP & 1.7 & $0.37 \%$ & \\
\hline $\mathrm{PE}$ & 1.1 & $0.24 \%$ & \\
\hline Aluminium, ingot & 2.7 & $0.56 \%$ & Positive electrode terminal \\
\hline Copper, billet & 8.8 & $1.87 \%$ & Negative electrode terminal \\
\hline \multicolumn{4}{|l|}{ Module packaging } \\
\hline Aluminium, ingot & 13.8 & $2.93 \%$ & Inner and outer frames of cells for heat conductance \\
\hline Copper, wire & 2.9 & $0.62 \%$ & Connection between modules \\
\hline Integrated circuit & 1.3 & $0.29 \%$ & Controller \\
\hline ABS & 6.1 & $1.30 \%$ & Module lid \\
\hline Polymer & 3.2 & $0.68 \%$ & Spacer between modules \\
\hline \multicolumn{4}{|l|}{ BMS } \\
\hline BMS & 4.0 & $0.85 \%$ & \\
\hline \multicolumn{4}{|l|}{ Cooling system } \\
\hline Aluminium, ingot & 7.8 & $1.65 \%$ & External heat radiator \\
\hline ethylene glycol & 20.0 & $4.26 \%$ & coolant \\
\hline \multicolumn{4}{|l|}{ Pack packaging } \\
\hline Aluminium, ingot & 42.4 & $9.02 \%$ & Pack housing \\
\hline Steel, billet & 2.5 & $0.53 \%$ & Strap for battery pack \\
\hline Copper wire & 0.9 & $0.19 \%$ & \\
\hline Total & 471 & $100 \%$ & \\
\hline
\end{tabular}


The energy consumption throughout the life cycle of Li-S battery pack is another major component of the LCI results. Figure 3 (numerical results provided in Table S24 in ESI) presents detailed information on primary energy embodied in the main materials, components, and processes for the Li-S battery pack. Here the primary energy refers to the non-renewable energy extracted from nature that has not been refined into any form of secondary energy (e.g. electricity or steam). As calculated, the life cycle primary energy consumption is $2.36 \mathrm{MJ} \mathrm{km}^{-1}$ while the battery use phase takes a share of $71 \%$. In this study, the primary energy consumption in the Li-S battery use phase is further broken-down into the electricity loss from the charger, during the battery charging and discharging (plug-to-battery output) process, and from the energy delivery process for driving the EV and supporting auxiliary systems (battery-to-wheel). In this study, it is found that the electricity loss accounts for $21 \%$ of total energy consumption during the use phase. Next to the battery use phase, battery manufacturing consumes $0.51 \mathrm{MJ}$ $\mathrm{km}^{-1}$ of primary energy, in which dry room conditioning and electrode drying account for $38 \%$ and $13 \%$ of the total manufacturing energy, respectively. GSC manufacturing is found consuming $0.089 \mathrm{MJ} \mathrm{km}^{-1}$, which can be traced mainly to the sonication process. The primary energy embedded in all Li-S materials is $0.16 \mathrm{MJ} \mathrm{km}^{-1}$, less than half of the primary energy demand for battery manufacturing.

In this study, it is found that the Li-S battery is mainly constructed from such bulk materials as sulfur (thiosulfate form), hydrochloric acid, aluminium and DME, which can be obtained with moderate environmental burdens. For example, the sodium thiosulfate, the largest material flow in the Li-S battery production (see Table 2), is a by-product of sodium sulfide production. Therefore, production of sodium thiosulfate consumes a limited amount of primary 
energy at $39.6 \mathrm{MJ} \mathrm{kg}^{-1}$. In comparison, GO synthesis is highly energy-intensive at $448 \mathrm{MJ} \mathrm{kg}^{-1}$, while the GO only takes $1.12 \mathrm{wt} \%$ share of the material flow in the Li-S cell.

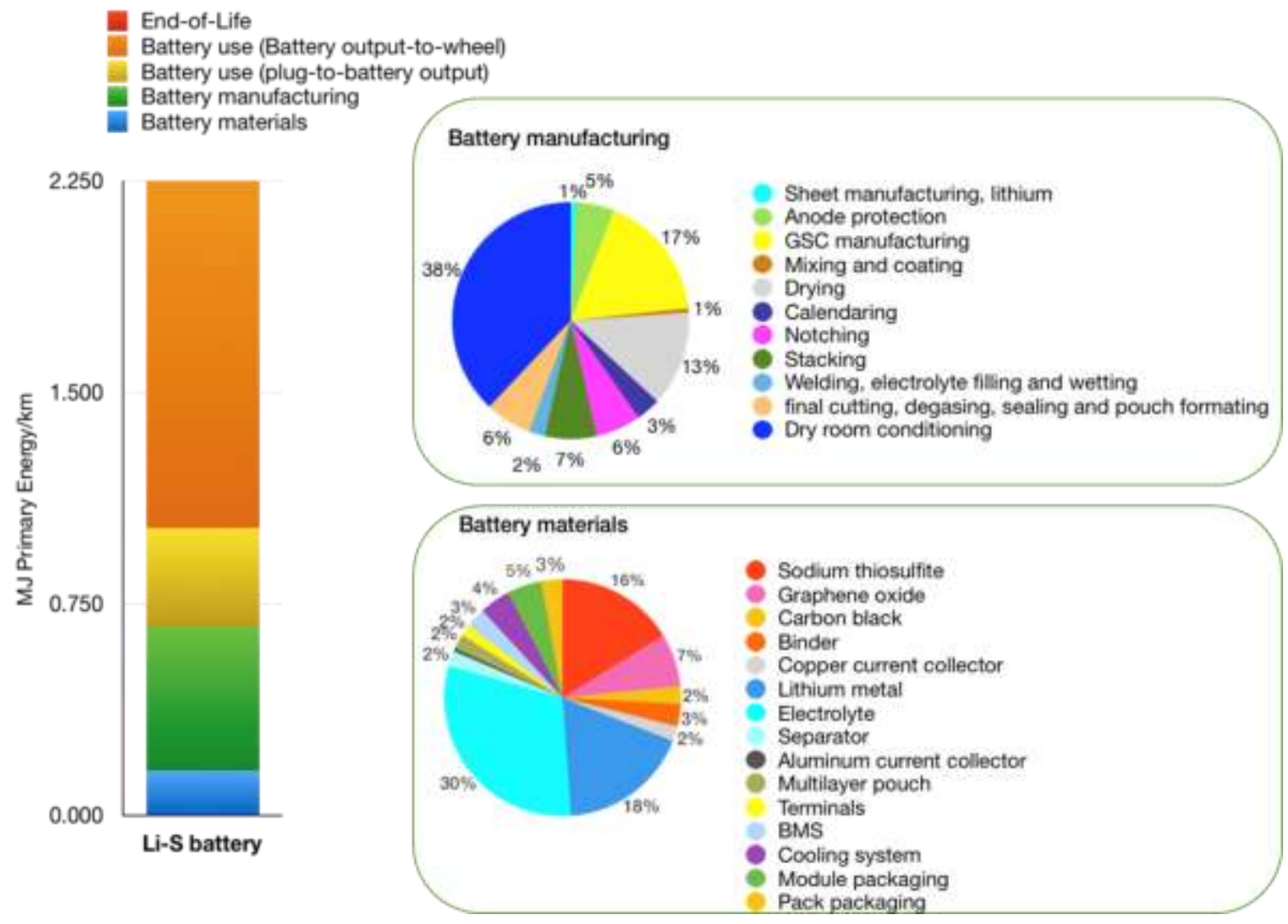

Figure 3 Distribution and primary energy consumption of Li-S battery pack during its life cycle. Numerical results are provided in Table S24

\subsection{Life Cycle Impact Assessment Results}

The life cycle environmental impacts of the Li-S battery are calculated using the ReCiPe method into 13 impact categories, and the hotspots are revealed by a contribution analysis in Figure 4. The pattern bars of Figure 4 represent the contributions of life cycle stages to the environmental impacts of the Li-S battery, including battery production (including all activities from raw material extraction to battery manufacturing), battery use (divided into plug-to-output 
and output-to-wheel), and EoL; the colored bars illustrate the contributions of each component of the Li-S battery pack to the environmental impacts of the battery production stage.

\subsubsection{Battery production.}

As shown in Figure 4, within the production phase, the Li-S battery cell manufacturing produced around $60 \%$ of share in both GWP and FDP impact categories. This is mainly caused by the intensive electricity consumption in the amount of $46.6 \mathrm{kWh} \mathrm{kg}^{-1}$ during the Li-S cell manufacturing. Electrode drying, which is used to evaporate NMP solvent from the cathode slurry, has been identified as the primary contributor with $13 \%$ of share. Electrode drying requires 192 mins processing time per cell under $150^{\circ} \mathrm{C}$ temperature. For each $87.5 \mathrm{Ah}$ Li-S cell manufacturing, drying consumes $8.2 \mathrm{kWh}$ electricity, while other battery manufacturing steps, including mixing, coating, calendaring, notching, and stacking, only consume $0.10-1.77 \mathrm{kWh}$. Besides, energy demand from the dry room facility in cell manufacturing is substantial as well. The dry room of the pilot scale facility in this study is operating at $64.8 \mathrm{~kW}$ demand, in which $41 \%$ is required by the heating and dehumidification machines. The energy intensity of cell manufacturing is expected to be significantly reduced when large scale production of Li-S batteries is implemented in the future. Through modelling industrial-scale processes, our study estimates that an energy consumption in the range of 11.3-22.8 $\mathrm{kWh} \mathrm{kg}^{-1}$ cell can be achieved for the large scale Li-S cell production. In comparison, Ellingsen et al. estimated an energy consumption of 28-112 $\mathrm{kWh} \mathrm{kg}^{-1}$ cell for the conventional NCM-Graphite cell production [7]. However, some other studies reported substantially lower energy consumption data for conventional LIB pack production only in the range of 1-5 $\mathrm{MJ} \mathrm{kg}^{-1}$ pack (around 1.6-8 $\mathrm{MJ} \mathrm{kg}^{-1}$ cell assuming $60 \%$ mass fraction of cells) [9], mainly because of ignoring the dry room facility in their studies. 
In this study, it is found that the positive electrode production takes a share of $7 \%-23 \%$ in most impact categories, which is mainly attributed to the considerable energy demand in GSC fabrication. Additionally, the positive electrode is the main impact source (48\%) of the MDP impact category, confirming the fact that positive electrode fabrication involves the majority of mass inputs in battery production.

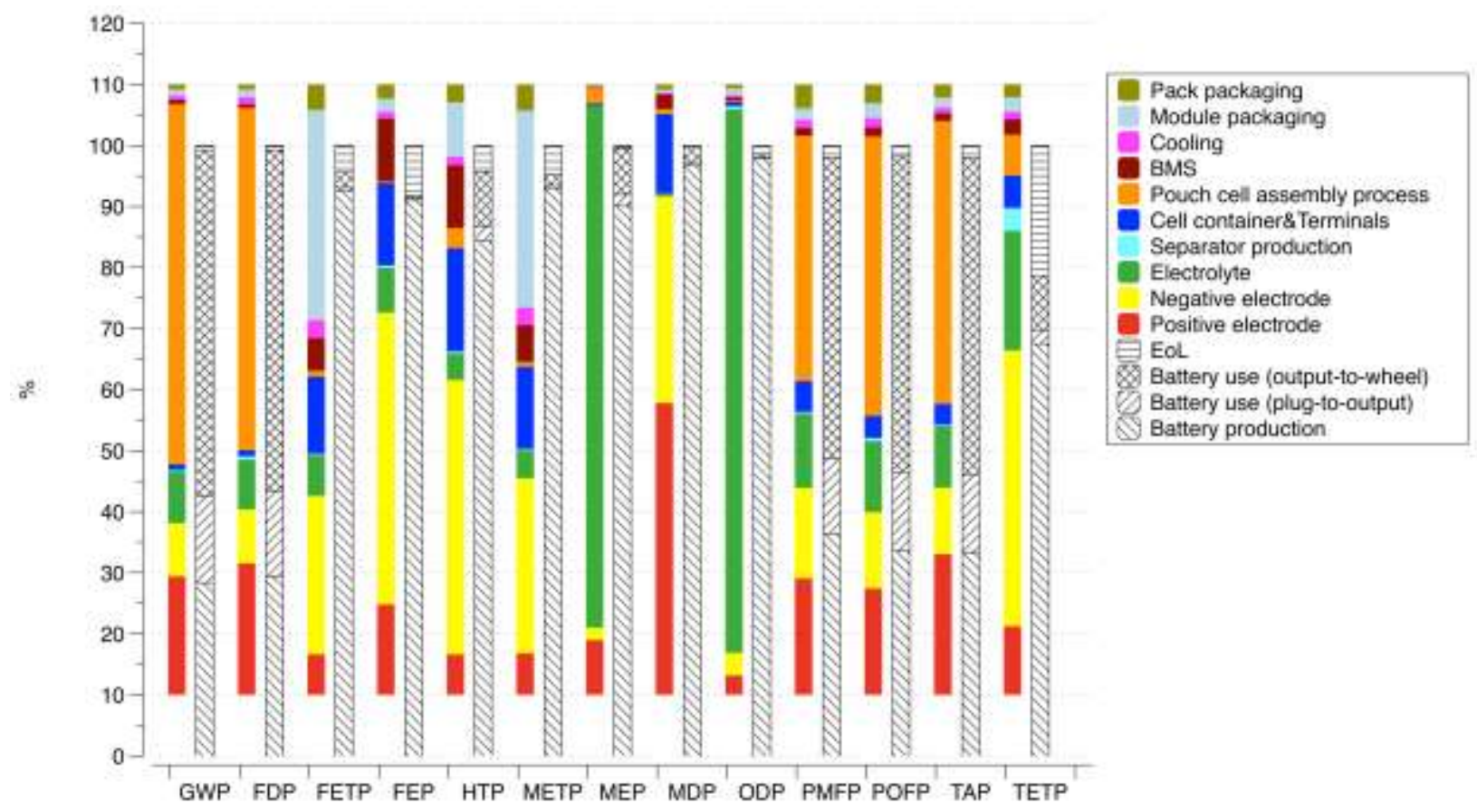

Figure 4 Contributions of Life cycle environmental impacts of the Li-S battery. Numerical results are provided in Table S25

The negative electrode, cell container, and module packaging are identified to be the main contributors to FETP, HTP, METP, and TETP impact categories. An in-depth analysis reveals that these toxicity impacts mainly stem from the copper uses as current collector and terminals, as well as the anodising process to produce the inner and outer aluminium frames in module packaging. This finding is largely consistent with the results of conventional NCMGraphite LIB production in Ellingsen et al.[7]. They found that the copper current collector is the dominant source $(>60 \%)$ for impacts in FETP, METP, TETP, and HTP. 
To assess the impact of the novel GO nanomaterial used in the Li-S battery, we have developed an ecotoxicity model based on the modified USEtox methodology incorporating colloidal theory to reflect the planar structure of GO, and found that the ecotoxicity characterization factor for GO emission is only $7.77 \times 10^{2} \mathrm{PAF} \mathrm{m}^{3}$ day $\mathrm{kg}^{-1}$ emitted [60]. In comparison, the ecotoxicity characterization factors of cobalt, copper, nickel, and manganese are several magnitudes higher, at $4.48 \times 10^{4}, 3.63 \times 10^{6}, 1.07 \times 10^{5}$, and $6.32 \times 10^{3} \mathrm{PAF} \mathrm{m}^{3}$ day $\mathrm{kg}^{-1}$ emitted, respectively [75]. With the derived characterization factor for GO, we employed the USEtox method to calculate the ecotoxicity impact of the Li-S battery. The release rate of GO during the production of the Li-S battery is assumed to be $0.2 \%$, the same as the emission rate of carbon nanotubes (CNTs) [76]. It is found that the ecotoxicity impact of GO is 1306 PAF $\mathrm{m}^{3}$ day, which accounts for only $2.9 \%$ of the ecotoxicity impact from the Li-S battery. For the 1306 PAF $\mathrm{m}^{3}$ day impact, the GO production produces $1070 \mathrm{PAF} \mathrm{m}^{3}$ day while the release of GO only incurs a small 8.2 PAF $\mathrm{m}^{3}$ day impact on ecotoxicity. The low ecotoxicity of GO nanoparticles is from several aspects. First, GO is a photodegradable material [77]. Fragmented GO is highly immobile in water due to the formation of irreversible aggregates and can be removed from water quickly with sediments [78]. Furthermore, humid acid, a widely present environmental substance, is an effective natural antidote which can neutralize the toxicity of GO [79]. On the other hand, past studies show that GO concentration in water needs to reach $50 \mathrm{mg} \mathrm{L}^{-1}$ level to generate effective cytotoxicity on human cells, indicating a limited human health impact [80]. Moreover, the uptake of GO in a human cell is subtle due to its high aspect ratio, which also reduces the risk of human impact [81]. During the EoL treatment, the GO can be degraded during the high-temperature process. Therefore, the toxicity impact of GO is expected to be negligible. 
Electrolyte contributes to about $21 \%$ of environmental impacts in Li-S battery pack production, but it accounts for a substantial environmental impact share over $85 \%$ in MEP and ODP categories. The significant contribution to the MEP impact category is found mainly from the synthesis of DME, with the associated ammonia and nitrate emissions. The significant impact share in ODP is mostly attributed to the large amount of methylchloride solvent used during the LiTFSI synthesis.

\subsubsection{Battery life cycle impacts.}

For the total life cycle impacts of the $61.3 \mathrm{kWh}$ Li-S battery pack, it is found that the battery production phase contributes $28 \%-36 \%$ to such categories as GWP, FDP, PMFP, POFP, and TAP, while 67\%-98\% to such categories as FETP, FEP, HTP, METP, MEP, MDP, ODP, TETP. However, the battery use phase contributes $70 \%$ to both the GWP and FDP impacts (Figure 4). The battery use phase is also a major contributor to the PMFP, POFP, and TAP, sharing $61 \%-65 \%$ of their life cycle impacts. Since electricity use is the only considered impact source during the battery use phase, the environmental burdens from battery use are mainly associated with the U.S. grid power generation and distribution. When compared, battery recycling contributes about $4 \%$ in most impact categories. The only exception is the TETP impact where a considerable $21 \%$ impact share is observed, because the battery pack is assumed to be treated with hydrometallurgical recycling process involving a significant amount of liquid nitrogen which triggers large impact in TETP.

\subsubsection{Comparison between Li-S and NCM-Graphite Battery Packs.}

To understand the relative significance of the environmental impacts of the Li-S battery, here the life cycle environmental impacts of the $61.3 \mathrm{kWh} \mathrm{Li-S} \mathrm{battery} \mathrm{pack} \mathrm{is} \mathrm{compared} \mathrm{with}$ 
those of a conventional $63.8 \mathrm{kWh}$ NCM-Graphite battery (Figure 5, Table S26 in the ESI for numerical results).

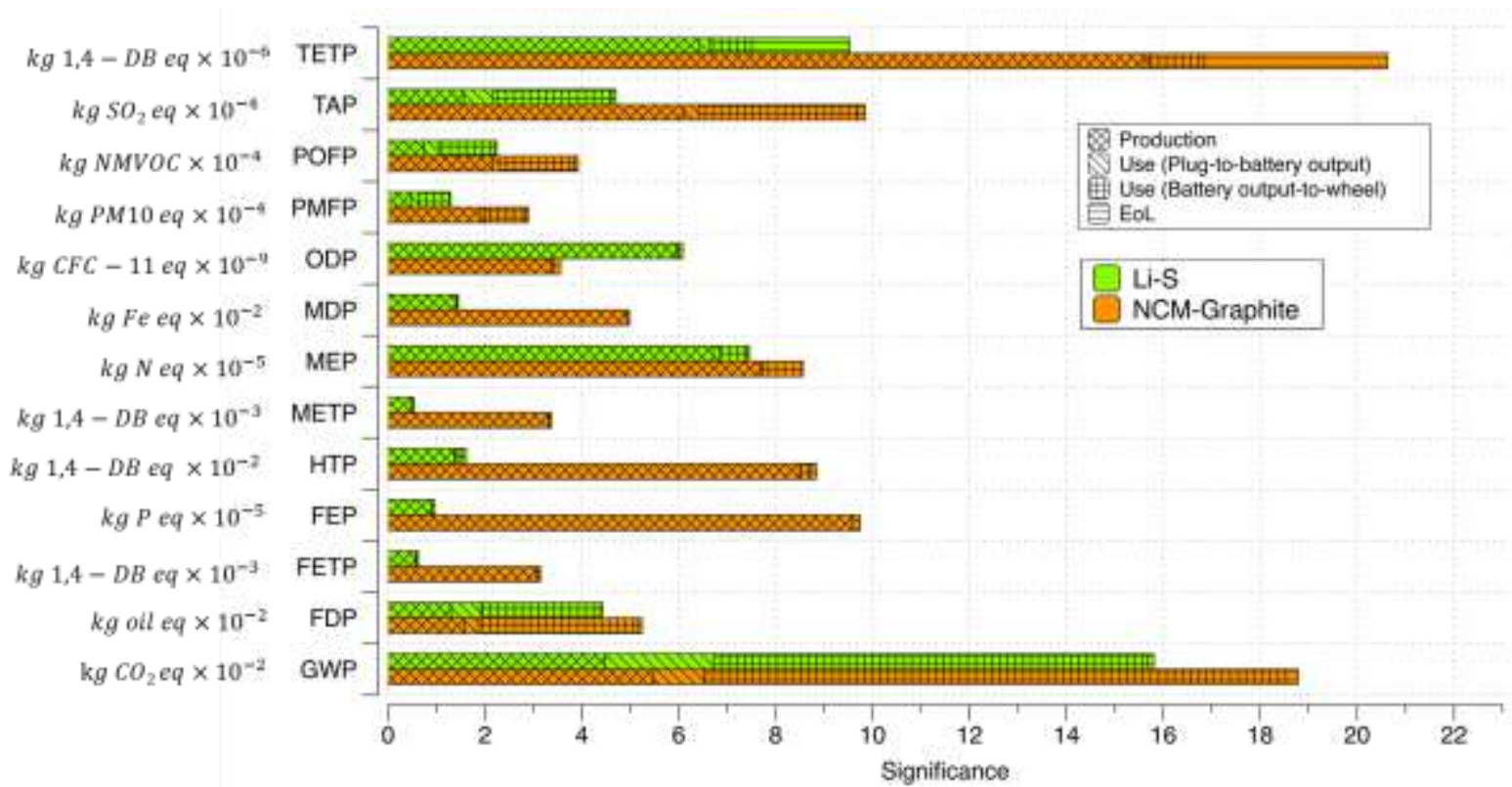

Figure 5 life cycle impact benchmarking between the Li-S and the NCM-Graphite battery packs.

As shown in Figure 5, the Li-S battery is more environmentally friendly than the conventional NCM-graphite battery technology. The calculated life cycle environmental impacts of the Li-S battery pack are $9 \%-90 \%$ lower than those corresponding impacts of the conventional NCM-Graphite battery, except for ODP where Li-S battery is $71 \%$ higher than the NCMGraphite battery. It must be noted that the environmental impacts of the Li-S battery are evaluated here in a mixed lab-scale and pilot production scale, while the NCM-Graphite battery is assessed on a full industrial-scale production capacity with the optimized level of energy intensity for cell manufacturing. In a partial production capacity, the life cycle environmental impacts of the NCM-Graphite battery can be further increased by $12 \%-40 \%$ in the GWP and FDP categories. As a result, the Li-S battery will have significantly lower impacts than the conventional NCM-Graphite battery when it reaches the same large industrial production scale in future. 
For GHG emission, the production of the Li-S battery generates $44.8 \mathrm{CO}_{2}$ eq km $\mathrm{km}^{-1}, 18.4 \%$ lower than the $54.9 \mathrm{CO}_{2}$ eq $\mathrm{km}^{-1}$ emission from the NCM-Graphite battery pack production. The lower impact of the Li-S battery in GWP can be mainly ascribed to those low-impact bulk materials such as sodium thiosulfate used in Li-S battery production. As calculated, the GHG emission from the battery use phase can be reduced from $117 \mathrm{~g} \mathrm{CO}_{2}$ eq $\mathrm{km}^{-1}$ from NCMGraphite battery to $112 \mathrm{~g} \mathrm{CO}_{2}$ eq km${ }^{-1}$ from the Li-S battery. Overall, a $9 \%$ of life cycle GHG emission reduction can be achieved from using the Li-S battery over the NCM-Graphite battery.

In addition, using a Li-S battery over a conventional NCM-Graphite battery can reduce $80-90 \%$ of impacts in such categories as FETP, METP, HTP, and TETP from the life cycle perspective, because the Li-S battery does not use heavy metals such as Nickel, Cobalt, and Manganese, and it uses much less copper than a conventional NCM-Graphite battery. As calculated, the $63.8 \mathrm{kWh}$ NCM-Graphite battery contains $26.3 \mathrm{~kg}$ cobalt, $26.0 \mathrm{~kg}$ nickel, $24.1 \mathrm{~kg}$ manganese and $84.8 \mathrm{~kg}$ copper. Ellingsen et al.[7] reported that productions of these heavy metal based components contribute more than $80 \%$ shares to FETP, HTP, METP and TETP during the NCM-Graphite battery production phase. When compared, the $61.3 \mathrm{kWh} \mathrm{Li-S} \mathrm{battery} \mathrm{contains}$ only $36.8 \mathrm{~kg}$ copper. The substantial reductions of the toxic metals in the Li-S battery cell make it an environmentally sustainable energy storage technology over conventional lithium-ion battery technologies.

\subsubsection{Sensitivity}

To evaluate the reliability and viability of the LCA results, a sensitivity analysis is conducted in this study to check the influences of the intrinsic variabilities of six major LCA parameters by changing their baseline values across potential ranges, including: driving range per charge (D), battery accessible capacity ratio (UR), total mileage (T), battery efficiency 
$\left(\eta_{\text {battery }}\right)$, energy consumption of cell manufacturing, and decay rates (r) of Li-S battery during actual EV operations. Detailed information is provided in Table 3.

Table 3 Parameter variations for sensitivity analysis

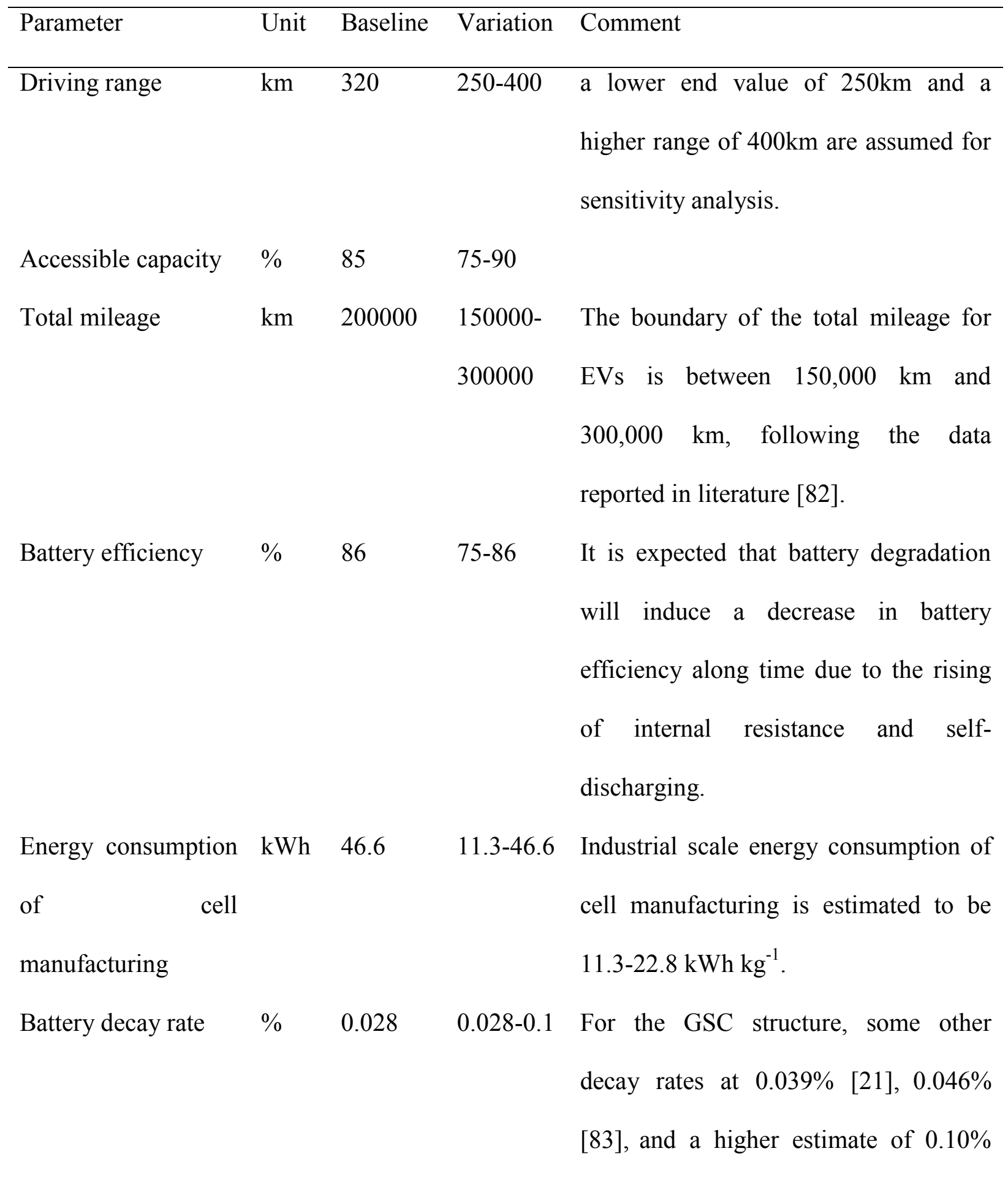


were reported in the literature,

Detailed results of the sensitivity analysis are presented in Figure S14 and Table S27 in ESI. Summarily, the sensitivity analysis provides numerical evidence that the life cycle impact assessments conducted on the Li-S battery and the benchmarking made between the Li-S battery and the conventional NCM-Graphite battery are viable. Except for the battery decay parameter (Figure S14(f)), the influences of other parameters on the LCA results are moderate, within 24\%-24\% variations from the baseline level (Figure S14(a)-(e)). When compared, the life cycle impacts of the Li-S battery are $9 \%-90 \%$ lower than those of the conventional NCM-Graphite battery except ODP (Figure 5). On the other hand, the baseline energy density of the NCMGraphite battery applied in the main text is $120 \mathrm{Wh} \mathrm{kg}^{-1}$. The state-of-the-art NCM-Graphite, as applied in Tesla Model S, reaches $140 \mathrm{Wh} \mathrm{kg}^{-1}$ nowadays [85]. A sensitivity analysis has been conducted with the energy density of $140 \mathrm{Wh} \mathrm{kg}^{-1}$ resulting $6 \%-12 \%$ decreases among various impact categories (Figure S15). Hence, a conclusion can be reliably made that the Li-S battery is more environmental-friendly than the conventional NCM-Graphite battery.

From the sensitivity analysis, it is noted that increasing the driving range from $320 \mathrm{~km}$ to $400 \mathrm{~km}$ per charge will increase the life cycle impacts in GWP and FDP by 9\% (Figure S14(a)). However, under such a case, the GWP and FDP of the conventional NCM-Graphite battery will be increased by $11 \%$ (Figure S16 in the ESI). Meanwhile, the scale-up of the Li-S production, with a $11.3 \mathrm{kWh} \mathrm{kg}^{-1}$ pouch cell assembly process, to the industrial scale will reduce the impacts in these two categories by $13 \%$ (Figure $\mathrm{S} 14(\mathrm{e})$ ). As a result, using a Li-S battery to replace the conventional NCM-Graphite battery will increase the driving range and reduce the life cycle impacts simultaneously in the future. 
It must also be noted here that past LCA studies tend to select the same storage capacity among various batteries for benchmarking $[10,84]$. Following this procotol, the same $61.3 \mathrm{kWh}$ NCM-Graphite battery pack will slightly lower the range to around $300 \mathrm{~km}$ per charge (Figure S17). Since previous studies show that the driving range of EVs is the major concern of consumers in market choice, and an acceptable driving range for an EV is expected to be $353 \mathrm{~km}$ and $437 \mathrm{~km}$ per charge, respectively, in Germany and the U.S.[86-88], the same driving range at $320 \mathrm{~km}$ is selected accordingly as the benchmarking basis in this study between the Li-S battery and the conventional NCM-Graphite battery.

\subsection{Future Improvement Potentials}

Current Li-S batteries are with a gravimetric energy density of $220 \mathrm{Wh} \mathrm{kg}^{-1}$ and volumetric energy density of $298 \mathrm{Wh} \mathrm{L}^{-1}$, which are still below the targets of U.S. Advanced Battery Consortium (USABC) set at $235 \mathrm{Wh} \mathrm{kg}^{-1}$ and $500 \mathrm{Wh} \mathrm{L}^{-1}$, respectively. In this study, we present a predictive study on the potential improvements of the Li-S battery performance via those key technical parameters including NP ratio, electrolyte fraction in the cathode, sulfur weight concentration in the cathode, and areal loading at three different production scales, as shown in Figure 6 [54]. The corresponding changes of the total environmental impacts along with these technical improvements are analysed, using the total ecopoints from the hierarchical perspective of the ReCiPe method. As predicted, the gravimetric energy density and volumetric energy density of the Li-S battery could be increased to $308 \mathrm{Wh} \mathrm{kg}^{-1}$ and $415 \mathrm{Wh} \mathrm{L}^{-1}$, respectively, with the NP ratio being reduced to 1.1 , electrolyte fraction decreased to $50 \%$, the sulfur weight concentration increased to $72 \%$, and the areal loading increased to $10.6 \mathrm{mAh} \mathrm{cm}^{-1}$. Corresponding, the total environmental impacts can be reduced by $20 \%$ in terms of the ecopoints. The pathway analysis indicates that a high areal loading is significant for the Li-S battery 
to meet the USABC target while maintaining a lower environmental impact. However, a thick electrode, triggered by such a high areal loading, will intensify dentride growth and sulfur shuttle effect in both anode and cathode. Therefore, further research on non-flammable electrolyte or solid electrolyte for the lithium sulfur battery are needed to solve the safety issue in future. For cathode, such approaches like constructing free-standing 3D electrodes and crosslinking nanostructured sulfur hosts are promising for developing high performance lithium sulfur batteries.

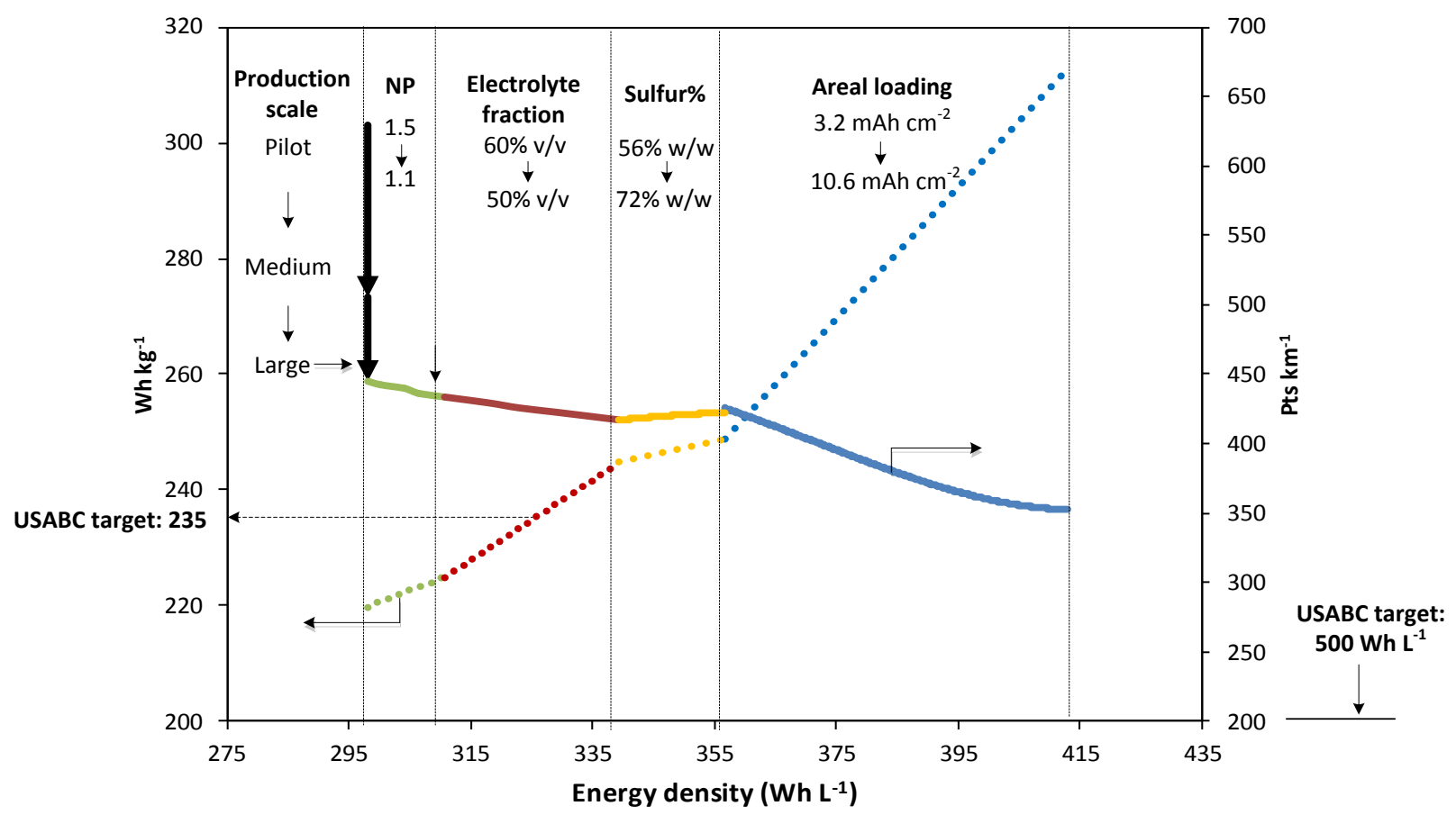

Figure 6 Pathways of the environmental impact changes of the Li-S battery in the production phase

Second, it is found in this study that the production of the nanostructured GSC cathode dominates the material flows during the life cycle of the Li-S battery. In particular, the sonication process used to create a homogenous dispersion of $\mathrm{GO}$ for sulfur precipitation is an energy intensive process. In the future, alternative energy-efficient technologies are needed to replace 
the sonication process for dispersion of GO nanoparticles. Besides, the cathode structure is a crucial factor determining the decay rate of Li-S battery, which in turn has a substantial influence on the environmental impacts of the Li-S battery. Future investigations are needed on optimal control of the size and the sediment speed of sulfur particles during the precipitation process to ensure an improved binding and wettability between sulfur and graphene, and then, to alleviate the decay rate

Thirdly, the environmental impacts of the Li-S battery can be further reduced through an improved recycling process [6]. Currently, there is no established recycling system available for the conventional LIBs due to economic viability [83]. However, the economic potential of the Li-S battery recycling could be quite promising. Unlike conventional LIBs built on lithium oxides, pure lithium metal is used in the Li-S battery. Automated disassembly methods such as eddy current and density separators can be used to recover lithium metals by taking advantage of its substantially low density. Meanwhile, LiTFSI salt in the electrolyte can be another valuable substance for recovery because LiTFSI is a chemically and thermally stable compound with high economic value.

\section{Conclusion}

In this paper, a comprehensive LCA model is developed to assess and understand the life cycle environmental impacts of Li-S batteries for next generation EV applications, based on our lab experimentation, our industrial partner's battery manufacturing processes, and literature data. The Li-S battery is configured with a $61.3 \mathrm{kWh}$ capacity capable of powering a mid-size EV for $320 \mathrm{~km}$ per charge. From the LCA study, a total of $471 \mathrm{~kg}$ material inputs is needed to generate the $279 \mathrm{~kg} \mathrm{Li}-\mathrm{S}$ battery pack. Sodium thiosulfate and hydrogen chloride, which are used for GSC synthesis, are the two most significant material inputs, representing $28.0 \%$ and $13.0 \%$ of mass 
flows during the life cycle of the Li-S battery, respectively. Moreover, this study obtained a 2.36 $\mathrm{MJ} \mathrm{km}^{-1}$ life cycle energy consumption for the configured $61.3 \mathrm{kWh} \mathrm{Li-S} \mathrm{battery.} \mathrm{For} \mathrm{the} \mathrm{life}$ cycle energy consumption, the battery use phase takes a share of $71 \%$, followed by battery manufacturing at $22 \%$, and battery materials processing at $7 \%$. The intensive energy consumption in battery manufacturing is found mainly on the electrode drying process of NMP evaporation and dry room conditioning for cell manufacturing. The life cycle impact assessment reveals that battery use accounts for $70 \%$ of life cycle GWP and FDP impacts while battery production represents $28 \%$.

The relative significances of the environmental impacts of the Li-S battery are compared with those of a conventional NCM-Graphite LIB at the same $320 \mathrm{~km}$ driving range. The results clearly show that the Li-S battery is a more environmentally friendly technology than the conventional NCM-Graphite battery, with 9\%-90\% lower impacts in most impact categories. Specifically, $158 \mathrm{~g} \mathrm{CO}_{2}$ eq km$~^{-1}$ is generated from a Li-S battery during its life cycle, compared with $174 \mathrm{~g} \mathrm{CO}_{2}$ eq km${ }^{-1}$ from an NCM-Graphite LIB. The reliability of the LCA study is evaluated through a sensitivity analysis on six key parameters, including driving distance per charge, the accessible ratio of Li-S battery capacity, total mileage, Li-S battery efficiency, energy consumption of Li-S cell manufacturing, and Li-S battery decay rate.

Based on the findings from the LCA, the Li-S battery can be a more sustainable energy storage technology for next generation EV applications. Further reduction of the life cycle environmental impacts of the Li-S battery can be made through employing a binder-free electrode, developing an energy-efficient process for nanoparticle dispersion, improving the decay rate of the Li-S battery, and recycling Li-S batteries from retired EVs.

Corresponding Author 
*E-mail:chris.yuan@case.edu; phone:216-368-5191; fax:216-368-6445.

Notes

The authors declare no competing financial interest.

Acknowledgement

Financial support from National Science Foundation (CBET-1351602) is gratefully acknowledged. The authors would also like to thank Johnson Control Inc. for technical support in the energy analysis of the battery cell manufacturing.

Reference

[1] EPA, Inventory of U.S. Greenhouse Gas Emissions and Sinks: 1990-2013, 2015.

[2] EPA, NHTSA, 2017 and Later Model Year Light-Duty Vehicle Greenhouse Gas Emissions and Corporate Average Fuel Economy Standards, 2017.

[3] P. Girardi, A. Gargiulo, P.C. Brambilla, A comparative LCA of an electric vehicle and an internal combustion engine vehicle using the appropriate power mix: the Italian case study, Int J LCA. 20 (2015) 1127-1142. doi:10.1007/s11367-015-0903-x.

[4] L.A.W. Ellingsen, B. Singh, A.H. Strømman, The size and range effect: lifecycle greenhouse gas emissions of electric vehicles, Environ. Res. Lett. 11 (2016) 054010. doi:10.1088/1748-9326/11/5/054010.

[5] H. Huo, H. Cai, Q. Zhang, F. Liu, K. He, Life-cycle assessment of greenhouse gas and air emissions of electric vehicles: A comparison between China and the U.S, Atmos. Environ. 108 (2015) 107-116. doi:10.1016/j.atmosenv.2015.02.073. 
[6] J.B. Dunn, L. Gaines, J. Sullivan, M.Q. Wang, Impact of recycling on cradle-to-gate energy consumption and greenhouse gas emissions of automotive lithium-ion batteries, Environ. Sci. Technol. 46 (2012) 12704-12710. doi:10.1021/es302420z.

[7] L.A.W. Ellingsen, G. Majeau-Bettez, B. Singh, A.K. Srivastava, L.O. Valoen, A.H. Stromman, Life Cycle Assessment of a Lithium-Ion Battery Vehicle Pack, J. Ind. Ecol. 18 (2014) 113-124. doi:10.1111/Jiec.12072.

[8] B. Scrosati, J. Garche, Lithium batteries: Status, prospects and future, J. Power Sources. 195 (2010) 2419-2430. doi:10.1016/j.jpowsour.2009.11.048.

[9] D.A. Notter, M. Gauch, R. Widmer, P. Wäger, A. Stamp, R. Zah, et al., Contribution of Li-Ion Batteries to the Environmental Impact of Electric Vehicles, Environ. Sci. Technol. 44 (2010) 6550-6556. doi:10.1021/es903729a.

[10] B. Li, X. Gao, J. Li, C. Yuan, Life cycle environmental impact of high-capacity lithium ion battery with silicon nanowires anode for electric vehicles, Environ. Sci. Technol. 48 (2014) 3047-3055. doi:10.1021/es4037786.

[11] D. Larcher, J.-M. Tarascon, Towards greener and more sustainable batteries for electrical energy storage, Nature Chem. 7 (2014) 19-29. doi:10.1038/nchem.2085.

[12] A. Manthiram, Y. Fu, Y.-S. Su, Challenges and Prospects of Lithium-Sulfur Batteries, Acc. Chem. Res. 46 (2012) 1125-1134. doi:10.1021/ar300179v.

[13] Y. Hou, J. Li, X. Gao, Z. Wen, C.Yuan, J. Chen.. 3D Dual-Confined Sulfur Encapsulated in Porous Carbon Nanosheets and Wrapped with Graphene Aerogels as Cathode for Advanced Lithium Sulfur Batteries, Nanoscale, 8 (2016), 8228-8235. doi: 10.1039/C5NR09037G. 
[14] A. Manthiram, Y. Fu, S.-H. Chung, C. Zu, Y.-S. Su, Rechargeable Lithium-Sulfur Batteries, Chem. Rev. 114 (2014) 11751-11787. doi:10.1021/cr500062v.

[15] A. Manthiram, S.-H. Chung, C. Zu, Lithium-Sulfur Batteries: Progress and Prospects, Adv. Mater. 27 (2015) 1980-2006. doi:10.1002/adma.201405115.

[16] A. Rosenman, E. Markevich, G. Salitra, D. Aurbach, A. Garsuch, F.F. Chesneau, Review on Li-Sulfur Battery Systems: an Integral Perspective, Adv. Energy Mater. 5 (2015). doi:10.1002/aenm.201500212.

[17] H. Kim, H.D. Lim, J. Kim, K. Kang, Graphene for advanced Li/S and Li/air batteries, J Mater Chem A. 2 (2014) 33-47. doi:10.1039/C3ta12522j.

[18] L. Ji, M. Rao, H. Zheng, L. Zhang, Y. Li, W. Duan, et al., Graphene Oxide as a Sulfur Immobilizer in High Performance Lithium/Sulfur Cells, J. Am. Chem. Soc. 133 (2011) 18522-18525. doi:10.1021/ja206955k.

[19] J.W. Kim, J.D. Ocon, D.W. Park, J. Lee, Functionalized Graphene-Based Cathode for Highly Reversible Lithium-Sulfur Batteries, ChemSusChem. 7 (2014) 1265-1273. doi:10.1002/cssc.201300782.

[20] X. Fang, H. Peng, A Revolution in Electrodes: Recent Progress in Rechargeable Lithium-Sulfur Batteries, Small. 11 (2015) 1488-1511. doi:10.1002/smll.201402354.

[21] Q. Pang, X. Liang, C.Y. Kwok, L.F. Nazar, Advances in lithium-sulfur batteries based on multifunctional cathodes and electrolytes, Nature Energy. 1 (2016) 16132. doi:10.1038/nenergy.2016.132.

[22] Y. Qiu, W. Li, W. Zhao, G. Li, Y. Hou, M. Liu, et al., High-rate, ultralong cycle-life lithium/sulfur batteries enabled by nitrogen-doped graphene, Nano Lett. 14 (2014) 4821-4827. doi:10.1021/n15020475. 
[23] M.-K. Song, Y. Zhang, E.J. Cairns, A Long-Life, High-Rate Lithium/Sulfur Cell: A Multifaceted Approach to Enhancing Cell Performance, Nano Lett. 13 (2013) 58915899. doi:10.1021/n1402793z.

[24] G. Li, J. Sun, W. Hou, S. Jiang, Y. Huang, J. Geng, Three-dimensional porous carbon composites containing high sulfur nanoparticle content for high-performance lithiumsulfur batteries, Nat Comms. 7 (2016) 10601. doi:10.1038/ncomms 10601.

[25] X. Gao, J. Li, D. Guan, C. Yuan, A scalable graphene sulfur composite synthesis for rechargeable lithium batteries with good capacity and excellent columbic efficiency, ACS Appl Mater Interfaces. 6 (2014) 4154-4159. doi:10.1021/am4057979.

[26] W. Xu, J. Wang, F. Ding, X. Chen, E. Nasybulin, Y. Zhang, et al., Lithium metal anodes for rechargeable batteries, Energy Environ. Sci. 7 (2014) 513-537. doi:10.1039/C3EE40795K.

[27] D. Wang, W. Zhang, W. Zheng, X. Cui, T. Rojo, Q. Zhang, Towards High-Safe Lithium Metal Anodes: Suppressing Lithium Dendrites via Tuning Surface Energy, Adv. Sci. (2016) 1600168. doi:10.1002/advs.201600168.

[28] G. Zheng, S.W. Lee, Z. Liang, H.-W. Lee, K. Yan, H. Yao, et al., Interconnected hollow carbon nanospheres for stable lithium metal anodes, Nat. Nanotechnol. 9 (2014) 618623. doi:10.1038/nnano.2014.152.

[29] M.S. Park, S.B. Ma, D.J. Lee, D. Im, S.-G. Doo, O. Yamamoto, A Highly Reversible Lithium Metal Anode, Sci. Rep. 4 (2014). doi:10.1038/srep03815.

[30] G.A. Umeda, E. Menke, M. Richard, K.L. Stamm, F. Wudl, B. Dunn, Protection of lithium metal surfaces using tetraethoxysilane, J. Mater. Chem. 21 (2011) 1593-1599. doi:10.1039/C0JM02305A. 
[31] Filippo Marchioni, Kurt Star, Erik Menke, Thierry Buffeteau, Laurent Servant, A. Bruce Dunn, et al., Protection of Lithium Metal Surfaces Using Chlorosilanes, Langmuir. 23 (2007) 11597-11602. doi:10.1021/la701662r.

[32] G.Q. Ma, Z.Y. Wen, M.F. Wu, C. Shen, Q.S. Wang, J. Jin, et al., A lithium anode protection guided highly-stable lithium-sulfur battery, Chem. Commun. 50 (2014) 14209-14212. doi:10.1039/C4cc05535g.

[33] Z. Liang, G. Zheng, C. Liu, N. Liu, W. Li, K. Yan, et al., Polymer Nanofiber-Guided Uniform Lithium Deposition for Battery Electrodes, Nano Lett. 15 (2015) 2910-2916. doi:10.1021/n15046318.

[34] A.C. Kozen, C.-F. Lin, A.J. Pearse, M.A. Schroeder, X. Han, L. Hu, et al., NextGeneration Lithium Metal Anode Engineering via Atomic Layer Deposition, ACS Nano. 9 (2015) 5884-5892. doi:10.1021/acsnano.5b02166.

[35] S. Zhang, K. Ueno, K. Dokko, M. Watanabe, Recent Advances in Electrolytes for Lithium-Sulfur Batteries, Adv. Energy Mater. 5 (2015) n/a-n/a. doi:10.1002/aenm.201500117.

[36] W.-T. Xu, H.-J. Peng, J.-Q. Huang, C.-Z. Zhao, X.-B. Cheng, Q. Zhang, Towards Stable Lithium-Sulfur Batteries with a Low Self-Discharge Rate: Ion Diffusion Modulation and Anode Protection, ChemSusChem. 8 (2015) 2892-2901. doi:10.1002/cssc.201500428.

[37] Y.V. Mikhaylik, I. Kovalev, R. Schock, K. Kumaresan, J. Xu, J. Affinito, High Energy Rechargeable Li-S Cells for EV Application: Status, Remaining Problems and Solutions, ECS Trans. 25 (2010) 23-34. doi:10.1149/1.3414001. 
[38] L. Wang, J. Liu, S. Yuan, Y. Wang, Y. Xia, To mitigate self-discharge of lithium-sulfur batteries by optimizing ionic liquid electrolytes, Energy Environ. Sci. 9 (2016) 224-231. doi:10.1039/C5EE02837J.

[39] S. Wu, R. Ge, M. Lu, R. Xu, Z. Zhang, Graphene-based nano-materials for lithiumsulfur battery and sodium-ion battery, Nano Energy. 15 (2015) 379-405. doi:10.1016/j.nanoen.2015.04.032.

[40] Oxis Energy, http://www.oxisenergy.com/technology/product/ (accessed 29.11.2016).

[41] A. Fotouhi, D.J. Auger, K. Propp, S. Longo, M. Wild, A review on electric vehicle battery modelling: From Lithium-ion toward Lithium-Sulphur, Renewable Sustainable Energy Rev. 56 (2016) 1008-1021. doi:10.1016/j.rser.2015.12.009.

[42] T.R. Frømyr, F. K. Hansen, T. X. Olsenrn, The Optimum Dispersion of Carbon Nanotubes for Epoxy Nanocomposites: Evolution of the Particle Size Distribution by Ultrasonic Treatment, Journal of Nanotechnology. 2012 (2012) 1-14. doi:10.1155/2012/545930.

[43] R. Arvidsson, D. Kushnir, B.A. Sandén, S. Molander, Prospective Life Cycle Assessment of Graphene Production by Ultrasonication and Chemical Reduction, Environ. Sci. Technol. 48 (2014) 4529-4536. doi:10.1021/es405338k.

[44] D.L.I. Wood, J. Li, C. Daniel, Prospects for reducing the processing cost of lithium ion batteries, J. Power Sources. 275 (2015) 234-242.

[45] M. Goedkoop, R. Heijungs, M. Huijbregts, A. De Schryver, J. Stuijs, R. van Zelm, ReCiPe 2008: a life cycle impact assessment method which comprises harmonised category indicators at the midpoint and the endpoint level, Ruimtelijke Odening en Milieubeheer, 2009. 
[46] P.A. Nelson, K.G. Gallagher, I. Bloom, BatPaC (Battery Performance and Cost) Software, (2015), Argonne National Laboratory, Chicago.

[47] US EPA, Dynamometer Drive Schedules, https://www.epa.gov/vehicle-and-fuelemissions-testing/dynamometer-drive-schedules. (accessed 29.11.2016)

[48] US EPA, Fuel economy guide 2008, 2008.

[49] C. Bauer, J. Hofer, H.-J. Althaus, A. Del Duce, A. Simons, The environmental performance of current and future passenger vehicles: Life cycle assessment based on a novel scenario analysis framework, Appl. Energy. 157 (2015) 871-883. doi:10.1016/j.apenergy.2015.01.019.

[50] J. Neubauer, A. Pesaran, C. Bae, R. Elder, B. Cunningham, Updating United States Advanced Battery Consortium and Department of Energy battery technology targets for battery electric vehicles, J. Power Sources. 271 (2014) 614-621. doi:10.1016/j.jpowsour.2014.06.043.

[51] G. Zheng, Q. Zhang, J.J. Cha, Y. Yang, W. Li, Z.W. Seh, et al., Amphiphilic Surface Modification of Hollow Carbon Nanofibers for Improved Cycle Life of Lithium Sulfur Batteries, Nano Lett. 13 (2013) 1265-1270. doi:10.1021/nl304795g.

[52] M. Helen, M.A. Reddy, T. Diemant, U. Golla-Schindler, R.J. Behm, U. Kaiser, et al., Single step transformation of sulphur to Li2S2/Li2S in Li-S batteries, Sci. Rep. 5 (2015) 12146. doi:10.1038/srep12146.

[53] L. Qie, C. Zu, A. Manthiram, A High Energy Lithium-Sulfur Battery with UltrahighLoading Lithium Polysulfide Cathode and its Failure Mechanism, Adv. Energy Mater. 6 (2016) 1502459. doi:10.1002/aenm.201502459. 
[54] D. Eroglu, K.R. Zavadil, K.G. Gallagher, Critical Link between Materials Chemistry and Cell-Level Design for High Energy Density and Low Cost Lithium-Sulfur Transportation Battery, J. Electrochem. Soc. 162 (2015) A982-A990. doi:10.1149/2.0611506jes.

[55] K.G. Gallagher, S. Goebel, T. Greszler, M. Mathias, W. Oelerich, D. Eroglu, et al., Quantifying the promise of lithium-air batteries for electric vehicles, Energy Environ. Sci. 7 (2014) 1555-1563. doi:10.1039/C3EE43870H.

[56] Z. Yuan, H.-J. Peng, T.-Z. Hou, J.-Q. Huang, C.-M. Chen, D.-W. Wang, et al., Powering Lithium-Sulfur Battery Performance by Propelling Polysulfide Redox at Sulfiphilic Hosts, Nano Lett. 16 (2016) 519-527. doi:10.1021/acs.nanolett.5b04166.

[57] Byd E6, http://www.byd.com/na/old/auto/e6.html (accessed 29.11.2016).

[58] O. Gröger, H.A. Gasteiger, J.-P. Suchsland, Review—Electromobility: Batteries or Fuel Cells? J. Electrochem. Soc. 162 (2015) A2605-A2622. doi:10.1149/2.0211514jes.

[59] I. Besselink, P. F. Van Oorschot and E. Meinders, Design of an efficient, low weight battery electric vehicle based on a VW Lupo 3L The 25th World Battery, Hybrid and Fuel Cell Electric Vehicle Symposium and Exhibition, Shenzhen, China, 2010

[60] Y. Deng, J. Li, M. Qiu, Y. Fan, J. Zhang, C. Yuan, Deriving Characterization Factors on Freshwater Ecotoxicity of Graphene Oxide Nanomaterials For Life Cycle Impact Assessment, Int J LCA. doi:10.1007/s11367-016-1151-4.

[61] W.S. Hummers Jr., R.E. Offeman, Preparation of Graphitic Oxide, J. Am. Chem. Soc. 80 (1958) 1339-1339. doi:10.1021/ja01539a017.

[62] W.W.-F. Leung, Centrifugal Separations in Biotechnology, Elsevier, Oxford, 2007. 
[63] A. Thekdi, S.U. Nimbalkar, Industrial Waste Heat Recovery - Potential Applications, Available Technologies and Crosscutting R\&D Opportunities, 2015. doi:10.2172/1185778.

[64] S. De Meester, J. Dewulf, L. Roes, M. Patel, Development of Basic Engineering modules for prospective estimations of the material flows and energy requirements, Ghent University, 2011.

[65] S. Thakur, G. Das, P.K. Raul, N. Karak, Green One-Step Approach to Prepare Sulfur/Reduced Graphene Oxide Nanohybrid for Effective Mercury Ions Removal, J. Phys. Chem. C. 117 (2013) 7636-7642. doi:10.1021/jp400221k.

[66] Hielscher-Ultrasound Technology, http://www.hielscher.com/i10000_p.htm (accessed 29.11.2016).

[67] M. Wakihara, O. Yamamoto, Lithium Ion Batteries:Fundamentals and Performance, Wiley-VCH Verlag GmbH, Weinheim, 2008.

[68] B Hovsepian, Rolling of lithium, US Pat. 3721 113, 1971.

[69] A. Chakrabarti, Design and Synthesis of New Electrolyte Systems for Lithium-ion Batteries, Ph.D thesis, Illinois Institute of Technology, 2008.

[70] H.J. Emeléus, The Chemistry of Fluorine and Its Compounds, Elsevier, 2013.

[71] J. Dunn, C. James, L. Gaines, K.G. Gallagher, Material and energy flows in the production of cathode and anode materials for lithium ion batteries, Chicago, 2014. http://www.ipd.anl.gov/anlpubs/2014/11/108520.pdf.

[72] Federal Highway Administration, Average Annual Miles per Driver by Age Group, http://www.fhwa.dot.gov/ohim/onh00/bar8.htm (accessed 29.11.2016). 
[73] S. Campanari, G. Manzolini, F. Garcia de la Iglesia, Energy analysis of electric vehicles using batteries or fuel cells through well-to-wheel driving cycle simulations, J. Power Sources. 186 (2009) 464-477. doi:10.1016/j.jpowsour.2008.09.115.

[74] S. Glöser, M. Soulier, L.A.T. Espinoza, Dynamic Analysis of Global Copper Flows. Global Stocks, Postconsumer Material Flows, Recycling Indicators, and Uncertainty Evaluation, Environ. Sci. Technol. 47 (2013) 6564-6572. doi:10.1021/es400069b.

[75] A.D. Henderson, M.Z. Hauschild, D. van de Meent, M.A.J. Huijbregts, H.F. Larsen, M. Margni, et al., USEtox fate and ecotoxicity factors for comparative assessment of toxic emissions in life cycle analysis: sensitivity to key chemical properties, Int J LCA. 16 (2011) 701-709. doi:10.1007/s11367-011-0294-6.

[76] M.J. Eckelman, M.S. Mauter, J.A. Isaacs, M. Elimelech, New perspectives on nanomaterial aquatic ecotoxicity: production impacts exceed direct exposure impacts for carbon nanotoubes, Environ. Sci. Technol. $46 \quad$ (2012) 2902-2910. doi:10.1021/es203409a.

[77] W.-C. Hou, I. Chowdhury, J. David G Goodwin, W.M. Henderson, D.H. Fairbrother, D. Bouchard, et al., Photochemical Transformation of Graphene Oxide in Sunlight, Environ. Sci. Technol. 49 (2015) 3435-3443. doi:10.1021/es5047155.

[78] I. Chowdhury, W.-C. Hou, D. Goodwin, M. Henderson, R.G. Zepp, D. Bouchard, Sunlight affects aggregation and deposition of graphene oxide in the aquatic environment, Water Res. 78 (2015) 37-46. doi:10.1016/j.watres.2015.04.001.

[79] Y. Chen, C. Ren, S. Ouyang, X. Hu, Q. Zhou, Mitigation in Multiple Effects of Graphene Oxide Toxicity in Zebrafish Embryogenesis Driven by Humic Acid, Environ. Sci. Technol. 49 (2015) 10147-10154. doi:10.1021/acs.est.5b02220. 
[80] L. Feng, Z. Liu, Graphene in biomedicine: opportunities and challenges, Nanomedicine. 6 (2011) 317-324. doi:10.2217/nnm.10.158.

[81] X. Zhang, W. Hu, J. Li, L. Tao, Y. Wei, A comparative study of cellular uptake and cytotoxicity of multi-walled carbon nanotubes, graphene oxide, and nanodiamond, Toxicol. Res. 1 (2012) 62-68. doi:10.1039/C2TX20006F.

[82] H.C. Kim, T.J. Wallington, Life-Cycle Energy and Greenhouse Gas Emission Benefits of Lightweighting in Automobiles: Review and Harmonization, Environ. Sci. Technol. 47 (2013) 6089-6097. doi:10.1021/es3042115.

[83] H. Chen, C.H. Wang, Y.F. Dai, S.Q. Qiu, J.L. Yang, W. Lu, L.W. Chen, Rational Design of Cathode Structure for High Rate Performance Lithium-Sulfur Batteries, Nano Letters, 15 (2015), 5443-5448. doi: 10.1021/acs.nanolett.5b01837

[84] D.A. Notter, K. Kouravelou, T. Karachalios, M.K. Daletou, N.T. Haberland, Life cycle assessment of PEM FC applications: electric mobility and $\mu$-CHP, Energy Environ. Sci. 8 (2015) 1969-1985. doi:10.1039/C5EE01082A.

[85] Tesla Model S Battery, http://enipedia.tudelft.nl/wiki/Tesla_Model_S_Battery, (accessed 29.12.2016).

[86] N.S. Pearre, W. Kempton, R.L. Guensler, V.V. Elango, Electric vehicles: How much range is required for a day's driving? Transp. Res. Part C Emerg. Technol. 19 (2011) 1171-1184. doi:10.1016/j.trc.2010.12.010.

[87] T. Franke, I. Neumann, F. Bühler, P. Cocron, J.F. Krems, Experiencing Range in an Electric Vehicle: Understanding Psychological Barriers, Appl. Psychology. 61 (2012) 368-391. doi:10.1111/j.1464-0597.2011.00474.x. 
[88] T. Franke, J.F. Krems, What drives range preferences in electric vehicle users? Transp. Policy. 30 (2013) 56-62. doi:10.1016/j.tranpol.2013.07.005. 